\begin{tabular}{|l|l|l|l|l|l|}
\hline MUNIBE Antropologia-Arkeologia & $n^{\circ} 71$ & $225-241$ & DONOSTIA & 2020 & ISSN 1132-2217 • elSSN 2172-4555 \\
\hline
\end{tabular}

\title{
La transformación histórica del paisaje de montaña en la vertiente atlántica del País Vasco: el caso de Aiako Harria (Oiartzun, Gipuzkoa)
}

\author{
Historical transformations of the mountain landscape in the Atlantic valleys \\ of the Basque Country: the case of Aiako Harria (Oiartzun, Gipuzkoa)
}

PALABRAS CLAVES: Arqueología forestal, paisajes de montaña, SIG, usos del suelo históricos, ganadería, seles.

GAKO-HITZAK: Baso arkeologia, mendi-paisaia, GIS, lurraren erabilera historikoak, abeltzaintza, saroiak.

KEY WORDS: Forest archaeology, mountain landscapes, GIS, historic landuses, husbandry, seles.

\section{Josu NARBARTE HERNANDEZZ(1,2), Eneko DEL AMO JIMÉNEZ(3)}

\section{RESUMEN}

Los paisajes de montaña son el reflejo de las interacciones entre los grupos sociales y su medio ambiente, que se materializan en el espacio mediante la activación de los recursos por medio de diversas prácticas sociales. Este trabajo propone el desarrollo de una metodología de prospección basada en el análisis combinado de las coberturas terrestres y de los artefactos presentes en el paisaje, con el fin de reconstruir la historia social, económica y ecológica que subyace a la configuración actual del paisaje de montaña de Aiako Harria (Oiartzun, Gipuzkoa). Ante la aparente ilegibilidad de unos espacios a menudo observados desde un prisma puramente naturalístico, los resultados alcanzados ponen de relieve la densidad histórica de unos paisajes que actualmente se encuentran, en contraste, sujetos a un fuerte proceso de marginalización

\section{LABURPENA}

Mendi-paisaiek gizarteen eta ingurugiroaren arteko elkar-eragina islatzen dute. Hau praktika sozial desberdinen bidez gauzatzen da espazioan, ingurugiroko baliabideak aktibatuz. Artikulu honetan, erregistro anitzeko miaketa arkeologikoan oinarritutako metodologia bat erabiltzea proposatzen du espazio hauek ikertzeko. Hala, lur-estalduren eta mendi-esparruetan presente dauden artefaktuen azterketa uztartu da, paisaiaren egungo itxuraren azpian dauden prozesu sozialak, ekonomikoak eta ekologikoak ikertzeko xedez. Lana Aiako Harrian zentratu da (Oiartzun, Gipuzkoa, Euskal Herria). Dokumentatutako praktika zaharrenak baso-bazkalekuen ustiapenarekin lotuta daude, horiek Erd Arotik garatu baitziren abeltzaintza- eta basogintza-sistema dibertsifikatuen baitan. Aro Berrian, laborantza-lurren hedapenak asentamendu sakabanatu baten sorrera ekarri zuen, baso-bazkalekuak neurri batean ordezkatuz. Kontrastean, XIX.-XX. mendeetan industriara bideratutako baso-plantazioak nagusitu ziren, eta horixe da oraindik bertako lur-estaldura nagusia. Egun, espazio hauek marjinalizazio-prozesu betean daude. Hala ere, egindako lanak argi erakutsi du Aiako Harriko paisaia epe-luzeko harreman sozio-ekologiko konplexuen ondorioa dela, ohiko ordenazio- eta kudeaketa-ereduek sustatutako ikuspegi naturalista hutsarekin kontrastean.

\section{ABSTRACT}

Mountain landscapes reflect past interactions between social groups and their environment, materialised in the space by the activation of environmental resources with a variety of social practices. This paper proposes the development of a multi-proxy archaeological survey methodology, based on the combined analysis of the landcovers and manufacts present in the landscape, with the purpose of reconstructing the social, economic and ecological history that lies beneath its present-day layout, taking as a case study the mountains of Aiako Harria (Oiartzun, Gipuzkoa, Basque Country). The oldest practices documented are wooded pastures, present in the area since the Middle Ages in the framework of diversified silvo-pastoral resource management systems. During the Modern period, the expansion of agrarian lands gave origin to new dispersed settlements, often constructed on previous wooded pastures. In contrast, the $19^{\text {th }}-20^{\text {th }}$ centuries are marked by the expansion of industry-oriented forest plantations, which are still nowadays the most common landcover. Despite their progressive marginalisation, these spaces therefore appear as historically built features reflecting complex interactions between societies and their environment, in contrast with the purely naturalistic optic that is widespread in the regulation and management of these spaces nowadays.

\footnotetext{
(1) Aranzadi Zientzia Elkartea, Arkeologia Historikoa saila. Zorroagagaina 11, 20014 Donostia (Gipuzkoa). Email: narbarte@ni.eus

(2) Universidad del País Vasco / Euskal Herriko Unibertsitatea. Grupo de Investigación en Patrimonio y Paisajes Culturales.

(3) Aranzadi Zientzia Elkartea.
} 


\section{INTRODUCCIÓN}

Los entornos de montaña, tradicionalmente considerados como espacios marginales y caracterizados por una "historia casi inmóvil" (Braudel, 1949) o incluso "sin historia" (Falque-Vert, 1997), vienen recibiendo una creciente atención por parte de la investigación histórica y arqueológica. Esto se ha traducido en una completa resignificación de los mismos, que han pasado a ser estudiados como espacios socialmente construidos. En efecto, en varios países europeos se viene desarrollando una «arqueología de la montaña», que ha optado por poner en el centro del debate el papel jugado, en este tipo de contextos, por las formas de apropiación del espacio, así como las prácticas jurisdiccionales, productivas o de gestión de los conflictos asociadas a las mismas, que inciden en la configuración de unos paisajes en continua transformación.

Entre los principales referentes de esta corriente, destacan los proyectos ejecutados por diversos grupos en ambas vertientes del Pirineo (p.ej., Rendu, 2003; Bal et al., 2010; Galop et al., 2011; Rendu et al., 2015; 2016; Gassiot, 2016; Gassiot \& Pèlachs, 2017; Palet et al., 2017; Gragson et al., 2015; 2020) y en los Apeninos (p.ej. Moreno, 1990; Cevasco, 2007; Cevasco \& Molinari, 2007; Stagno, 2016; 2017; 2018), entre otras regiones del sur de Europa ${ }^{1}$. Enfoques similares se han ensayado también en el País Vasco, con trabajos desarrollados en Aralar (Mujika et al., 2003; Mujika \& Moraza, 2005), Aizkorri (Stagno, 2019; Stagno et al., 2020) o los montes de Vitoria (Martínez Montecelo \& Rodríguez Fernández, 2013). Estos trabajos han contribuido a cuestionar la noción de la montaña como un entorno "marginal", cuyo carácter de espacio históricamente producido rara vez llega a explicitarse, y que la planificación territorial tiende a relegar a figuras de naturalización y usos recreativos. En lugar de ello, el creciente corpus de información disponible subraya la necesidad de reconsiderar los paisajes de montaña como el resultado de largas interacciones entre el medio ambiente y las sociedades locales, en concordancia con lo que se ha venido subrayando también desde otras disciplinas como la antropología o la ecología (p.ej. Reyes-García \& Martí-Sanz, 2007; Molina et al., 2009; Calvet-Mir et al., 2012; Reyes-García et al., 2014; Hernández-Morcillo et al., 2015; Guadilla-Sáez et al., 2019; 2020). La huella material de estas interacciones se traduce en la activación de los recursos agro-silvo-pastorales mediante la puesta en marcha de determinadas prácticas sociales, y por tanto en una presión selectiva tanto sobre el medio como sobre las poblaciones bióticas presentes en el mismo.

El estudio de estas cuestiones pasa necesariamente por adoptar una perspectiva local, orientada a reconstruir la densidad histórica de las relaciones so- ciales y ecológicas que han convergido en los espacios de montaña (Moreno, 1990; Cevasco, 2007). En este sentido, una de las principales aportaciones metodológicas de la arqueología de la montaña ha consistido en subrayar la necesidad de combinar registros diversos procedentes de la prospección sobre el terreno: estructuras como rediles, cabañas o muros parcelarios; ecofactos generados por el manejo de determinados elementos vegetales; o coberturas terrestres indicativas de usos específicos presentes y pasados.

Sin embargo, esta aproximación local basada en la prospección presenta también algunos problemas, principalmente relacionados con las dificultades derivadas de una toma de datos pensada por y para el caso de estudio individual, lo cual dificulta la comparación entre contextos diferentes. El reciente desarrollo de los Sistemas de Información Geográfica y su aplicación a la investigación arqueológica han abierto la puerta a una mayor sistematización en las prospecciones realizadas en las áreas de montaña del sur de Europa, si bien la implementación de estas herramientas no se ha desarrollado todavía en todo su potencial. Sobre esta base, el objetivo del presente trabajo consiste en presentar el diseño y desarrollo de una metodología específica de prospección y georreferenciación para el estudio arqueológico del paisaje de montaña, con el fin de documentar las huellas de distintas prácticas y analizar la evolución de las interacciones sociales y ecológicas que han dado lugar al paisaje actual, así como de testar su capacidad para generar información significativa que pueda ser confrontada con otros registros históricos, como las fuentes documentales, la toponimia o la evidencia arqueológica.

En las páginas sucesivas, se presenta el área de estudio seleccionada para llevar a cabo el trabajo (Sección 2), pasando a continuación a desgranar la metodología diseñada a tal fin (Sección 3). La Sección 4 recoge los resultados obtenidos, que son discutidos en la Sección 5. Finalmente, la Sección 6 plantea, a modo de conclusión, las principales líneas de reflexión que se derivan del trabajo desarrollado.

\section{2. ÁREA DE ESTUDIO}

El área elegida para llevar a cabo este proyecto ha sido Aiako Harria (Gipuzkoa), un batolito granítico de $10 \mathrm{~km}$ de longitud que divide las cuencas hidrográficas del Urumea, el Bidasoa y el Oiartzun (Fig. 1). El macizo forma la Zona de Especial Conservación de Aiako Harria (ES2120016), con 6780 hectáreas distribuidas en cinco municipios. La mayor parte de su superficie se gestiona como Montes de Utilidad Pública (MUP) por la Diputación Foral de Gipuzkoa. El trabajo se ha centrado en la porción de la ZEC incluida en el término municipal

\footnotetext{
1 Otro ejemplo es el reciente proyecto Mediterranean Mountain Landscapes, desarrollado en Andalucía, Véneto, Apulia y Albania: <memolaproject.eu> (consulta: 18/12/2019).
} 
de Oiartzun, un espacio lo suficientemente amplio que alberga una gran diversidad de coberturas terrestres y usos del suelo, susceptibles de ser comparados entre sí. Además, existe una sólida base de estudios previos basados en las fuentes documentales para este entorno, que han sido empleados como elemento de control del trabajo desarrollado.

Estos montes corresponden a antiguos términos comunales en los que puede documentarse una gran diversidad de usos, intereses y actores sociales. Por un lado, la alta concentración de ferrerías hidráulicas, atestiguada desde el siglo XIV (Díez de Salazar, 1997), ha copado históricamente una gran parte de la producción de carbón vegetal de estos bosques (Aragón, 2001). Por otro lado, la cercanía de la costa estimuló la demanda de madera destinada a la industria naval (Odriozola, 2002; Aragón, 2001; 2009a). Ahora bien, aunque la actividad forestal haya tenido un gran peso en la zona, no se ejerció nunca en régimen de monocultivo, sino que se integró en un sistema multifuncional que incluía también ganadería y agricultura, propician- do complejos diálogos entre territorio y grupos sociales (Aragón Ruano, 2013; 2015).

La situación cambió tras los procesos desamortizadores de comienzos del siglo XIX (Mutiloa, 1982; Otaegui, 1991). Aunque, en el caso de Aiako Harria, estos no supusieron una privatización de los montes públicos, sí se dieron cambios relevantes en su gestión. Además, la revolución industrial contribuyó también al abandono de los manejos tradicionales, al tiempo que propiciaba la expansión de plantaciones forestales de crecimiento rápido, principalmente destinadas a alimentar la industria papelera. En los últimos años, la declaración de Parque Natural (EHAA, 105, 1995-06-05) ha dotado al espacio de una figura de protección ambiental. La aprobación del Plan Rector de Uso y Gestión (EHAA, 81, 2002-05-02) y el posterior desarrollo de normativas en el marco de la Directiva 92/43/CEE de Hábitats (EHAA, 224, 2013-11-25) han puesto el acento en la preservación de sus valores naturales; lo que, junto con el abandono de los manejos tradicionales, ha acentuado su aprovechamiento como espacio para el desarrollo de actividades recreativas.

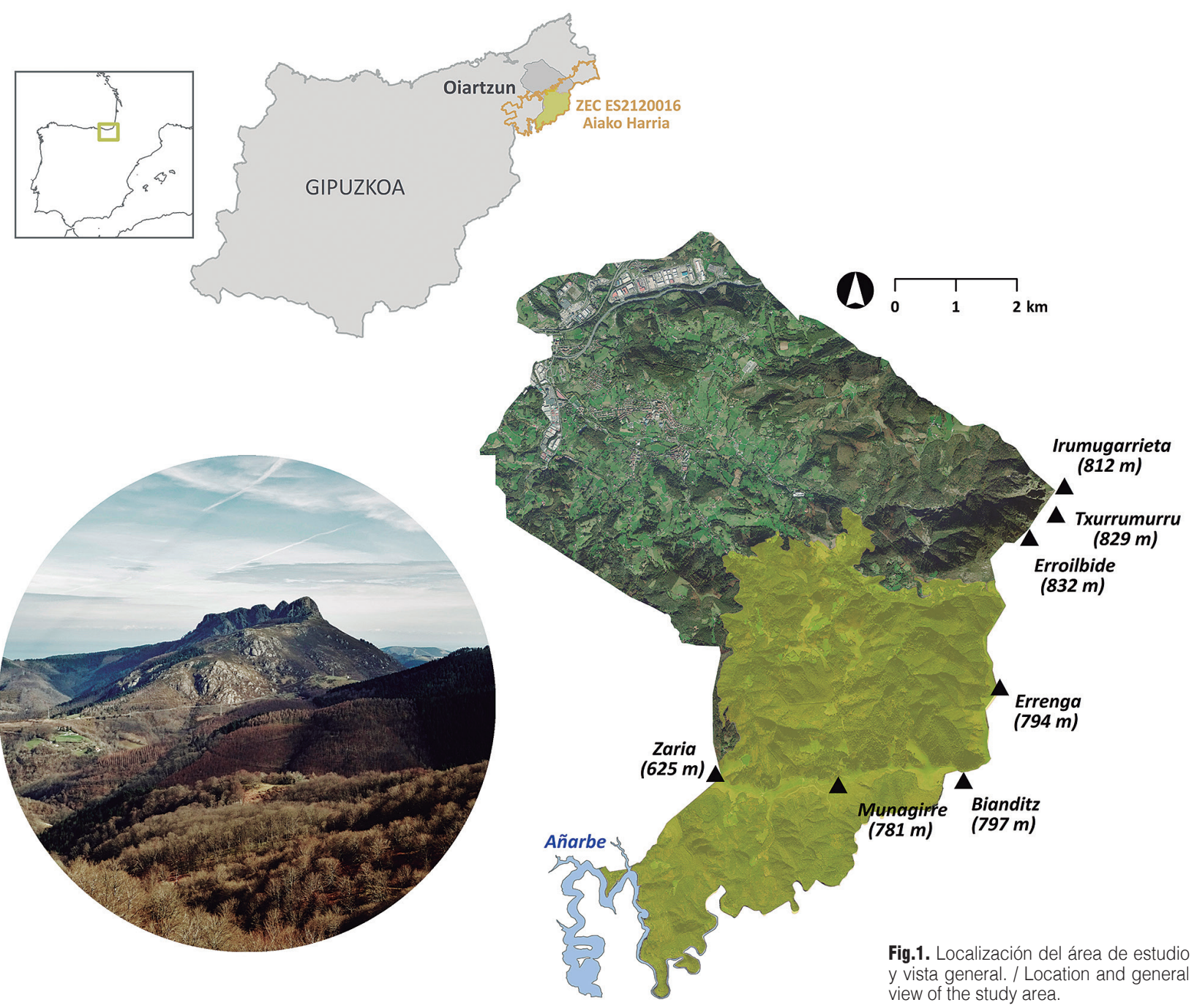




\section{METODOLOGÍA}

Partiendo del planteamiento inicial, se optó por una estrategia de prospección exhaustiva sobre el terreno, desarrollada entre 2017 y 2018. Una vez definidos los objetivos del trabajo, éste se llevó a cabo en tres pasos: 1) diseño de la base de datos en la que se iba a centralizar la información, 2) definición de un procedimiento sistemático de toma y gestión de los datos, y 3) generación de la cartografía final.

\subsection{Diseño de la base de datos}

La base de datos se diseñó teniendo en cuenta las características de la información a prospectar. Por ello, se optó por documentar simultáneamente dos tipos de evidencias, cada una con sus propias características:

- Coberturas terrestres ${ }^{2}$, un indicador de gran interés para documentar la evolución de los usos del suelo ${ }^{3}$. Se puso especial atención en distinguir las superficies arboladas que son el resultado de una gestión planificada de aquéllas donde la vegetación espontánea ha brotado tras el abandono de esta.

- Artefactos ligados a prácticas sociales diversas, desde los elementos de origen antrópico más visibles (caleros, muros, mojones, cabañas o terraplenes) hasta aquellos elementos vegetales que, debido al manejo al que han sido sometidos, actúan como biomarcadores de prácticas específicas de apropiación (límites parcelarios, marcadores de acceso) o gestión (árboles viejos, masas monoespecíficas). En este último apartado destacan los árboles trasmochos, que se documentaron siguiendo las propuestas de catalogación de Pardo et al. (2003) y Hazi Fundazioa (2014).

La herramienta metodológica adoptada para gestionar conjuntamente ambos tipos de datos fue la Unidad Topográfica. Esta noción, entendida como la síntesis de las acciones y procesos que tienen lugar en una unidad de superficie determinada, permite leer estratigráficamente los distintos elementos presentes en ella, ofreciendo información relevante sobre su evolución en el tiempo (Gattiglia \& Stagno, 2005). A su vez, las distintas Unidades Topográficas fueron agrupadas en Unidades de Paisaje de carácter más amplio (Pintó, 2010), de forma que no sólo se relacionaran los componentes antropogénicos y medioambientales, sino que también fuera posible definir sus pautas de evolución en el conjunto de Aiako Harria.

\subsection{Gestión de la información geográfica}

Las herramientas empleadas para el almacenamiento, sistematización y análisis de los datos fueron seleccionadas de acuerdo con los requerimientos técnicos del proyecto, con los objetivos específicos de: 1) facilitar la toma de datos; 2) centralizar la información; 3) favorecer la integridad y la calidad de los datos; 4) realizar análisis atendiendo a diferentes variables espaciales y territoriales; 5) obtener resultados y generar escenarios; 6) comparar resultados; 7) divulgar y crear información fácilmente compartible.

En una primera fase, se procedió a generar una estructura digital que funcionara como repositorio, aportando centralidad a toda la información recabada. Para ello se optó por la creación de una Personal Geodatabase (GdB) de ArcGIS 10.3, con una precisión de 0,01 metros y el sistema de referencia ETRS89 (European Terrestrial Reference System 1989). La GdB de base estuvo formada por un Dataset (fichas) con dos Features (geometría de puntos), una para cada tipo de ficha (coberturas terrestres; artefactos). En ellas se volcaron secuencialmente los datos tomados en campo por los equipos de prospección. Para asegurar la integridad de datos incorporados a la geodatabase, se definieron en su estructura una serie de dominios.

Las prospecciones se llevaron a cabo empleando el software libre OruxMaps. Se obtuvieron, así, unos archivos de información geográfica subdivididos en dos categorías (fichas de coberturas terrestres y fichas de artefactos), que reportaban de manera sistematizada el transecto realizado con las distancias recorridas y los rangos altitudinales, la información alfanumérica referente al elemento prospectado y una fotografía, todo ello correctamente georreferenciado.

El primer control de calidad tenía lugar en el momento de cargar los datos en la GdB, pues el propio diseño incluía una serie de dominios predeterminados. Adicionalmente se implementaron varios controles automáticos mediante expresiones SQL, que garantizaron la coherencia de los datos. Además de estos controles alfanuméricos para la carga de datos y su gestión, implícitamente en la definición de la GdB se habían establecido unos criterios de topología y coherencia espacial que permitieron que la información tuviera un sentido espacial único y fuera comparable, sin errores relativos a su disposición espacial.

Durante las prospecciones, la información geográfica se fue capturando en capas de puntos independien-

\footnotetext{
2 Atendiendo a la definición propuesta por el Sistema de Ocupación del Suelo de España (SIOSE), el término cobertura fue empleado para describir objetivamente y de forma representativa el material físico existente sobre la superficie terrestre.

${ }^{3}$ El estudio de los usos históricos del suelo ha sido ampliamente desarrollado en otras zonas de Europa, que empiezan en algunos casos a contar con sólidas síntesis territoriales. Es el caso de Escocia, que cuenta con un portal destinado específicamente a esta cuestión: https:// hlamap.org.uk/content/about-hla (consulta: 27/10/2020).
} 
tes, georreferenciados, cuyo posterior geoprocesamiento y volcado a la GdB de destino posibilitó la carga de datos sin pérdida de calidad alfanumérica y geográfica. Estos puntos, tanto por su localización como por la información que poseían, fueron la base para el desarrollo de la interpretación y digitalización de polígonos que conformarían las unidades espaciales de análisis (Unidades Topográficas y Unidades de Paisaje).

\subsection{Generación de resultados}

Tanto las fichas de coberturas como las de estructuras se usaron como base para la generación de polígonos espaciales con el software ArcGIS 10.3. Para la digitalización de la información tomada en campo -ocasionalmente completada con datos historiográficos, toponímicos y etnográficos_-, fue necesario realizar también una labor de fotointerpretación, basado en las fotografías aéreas de 1945-1946 y 1956-1957 y en la ortofotografía de la CAV correspondiente al año 20164. Los polígonos generados pueden clasificarse en tres grupos:

- Coberturas terrestres. Se digitalizaron en primer lugar a partir de los datos tomados en campo. Los polígonos obtenidos fueron cotejados y completados usando la cartografía digital del Inventario Forestal Nacional (Fig. 2a).
- Unidades de Paisaje. Para su generación se realizaron agrupaciones de coberturas y elementos que tienen un sentido y unas dinámicas comunes en el territorio. Además de la fotointerpretación, para la digitalización de Unidades de Paisaje fue fundamental la capa de coberturas terrestres generada en el paso anterior, así como la consideración de rangos altitudinales con el Modelo Digital de Elevaciones (Fig. 2b).

- Unidades Topográficas. Dentro de cada unidad de paisaje se identificaron las diferentes unidades topográficas en las que se observa una concentración significativa de elementos que establecen entre sí relaciones espaciales y estratigráficas, y son susceptibles por tanto de obtener información acerca de su evolución histórica.

Finalmente, el sistema de trabajo basado en el uso de Geodatabases posibilitó asegurar la integridad geográfica de los resultados mediante unos controles topológicos. Es decir, permitió implementar condiciones y restricciones desde el punto de vista espacial y controlar la digitalización de las geometrías en base a una serie de condiciones impuestas de antemano, para evitar que existieran huecos dentro de una capa o que los distintos polígonos se solapasen.
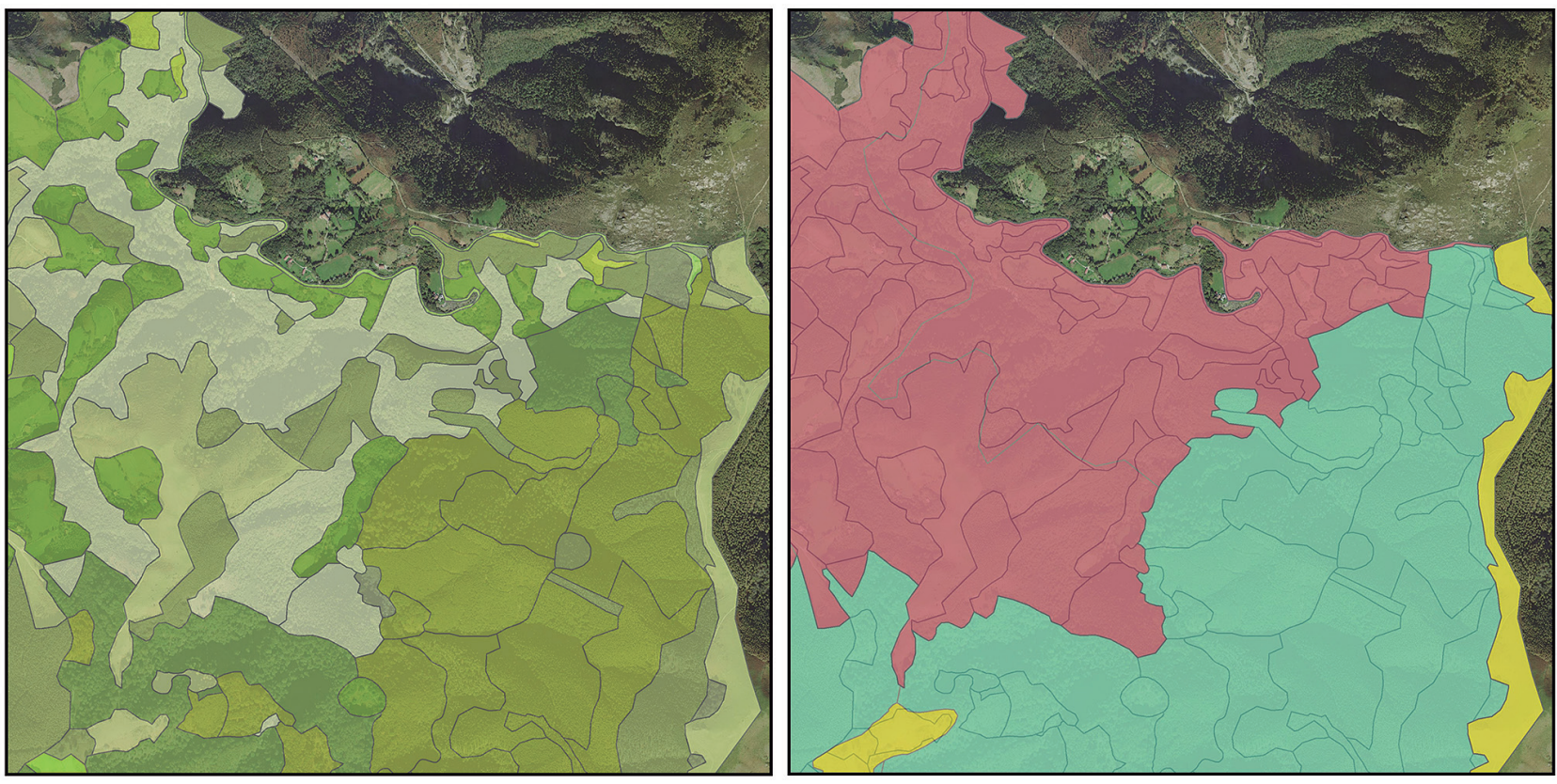

Fig.2. Proceso de fotointerpretación y digitalización. (a) Digitalización de coberturas terrestres. (b) Digitalización de Unidades de Paisaje a partir de las coberturas definidas. / Process of photo-interpretation and digitalisaton. (a) Digitalisation of landcovers. (b) Digitalisation of Landscape Units on the basis of pre-defined landcovers.

${ }^{4}$ Todas ellas alojadas en el servidor GeoEuskadi: www.geoeuskadi.eus (consulta: 27/10/2020). 


\section{RESULTADOS}

La superficie prospectada cubre 2367,2 hectáreas. Se ha documentado una amplia diversidad de huellas materiales — coberturas (Tabla I) y artefactos (Tabla II)—

\begin{tabular}{|c|c|c|}
\hline Cobertura & Superficie (ha) & Porcentaje \\
\hline Bosque mixto atlántico & 477,6 ha & $20,17 \%$ \\
\hline Hayedo & 44 ha & $1,86 \%$ \\
\hline Hayedo trasmocho & 256,2 ha & $10,82 \%$ \\
\hline Marojal / Robledal trasmocho & 3,8 ha & $0,16 \%$ \\
\hline Pastos cultivados y cultivos & 190,4 ha & $8 \%$ \\
\hline Pastos de montaña & 491,8 ha & $20,78 \%$ \\
\hline Plantaciones forestales & 878,7 ha & $37,12 \%$ \\
\hline Vegetación de ribera & 9,9 ha & $0,42 \%$ \\
\hline Otras & 14,7 ha & $0,62 \%$ \\
\hline TOTAL & $\mathbf{2 3 6 7 , 2}$ ha & $\mathbf{1 0 0} \%$ \\
\hline
\end{tabular}

Tabla 1: Extensión de las diferentes coberturas identificadas. / Spatial extent of the different landcovers identified. asociadas a una intensa apropiación y explotación de los recursos forestales, que forman un paisaje complejos y articulados, continuamente reformulado por medio de prácticas de acceso y aprovechamiento ${ }^{5}$. El análisis combinado de todas estas evidencias permite identificar numerosas unidades topográficas que pueden, a su vez, agruparse en tres unidades de paisaje (Fig. 3; Tabla III).

\begin{tabular}{|c|c|c|}
\hline Tipos & Cantidad & Total \\
\hline Árboles singulares & 42 & \\
\cline { 1 - 2 } Caleras & 6 & \\
\cline { 1 - 2 } Carboneras & 193 & \multirow{2}{*}{387} \\
\cline { 1 - 2 } Edificios (caseríos, establos, bordas, cabañas) & 41 & \\
\cline { 1 - 2 } Setos / Muros de piedra seca & 15 & \\
\cline { 1 - 2 } Aterrazamientos & 7 & \\
\cline { 1 - 2 } Biomarcadores & 4 & \\
\hline Otros & 79 & \\
\hline
\end{tabular}

Tabla 2: Cuantificación de los artefactos documentados. / Quantification of the artefacts detected.

Fig.3. Unidades de Paisaje y Unidades Topográficas identificadas en Aiako Harria Los números remiten a la Tabla III. / Landscape Units and Topographic Units defined in Aiako Harria. Numbers refer to Table III.
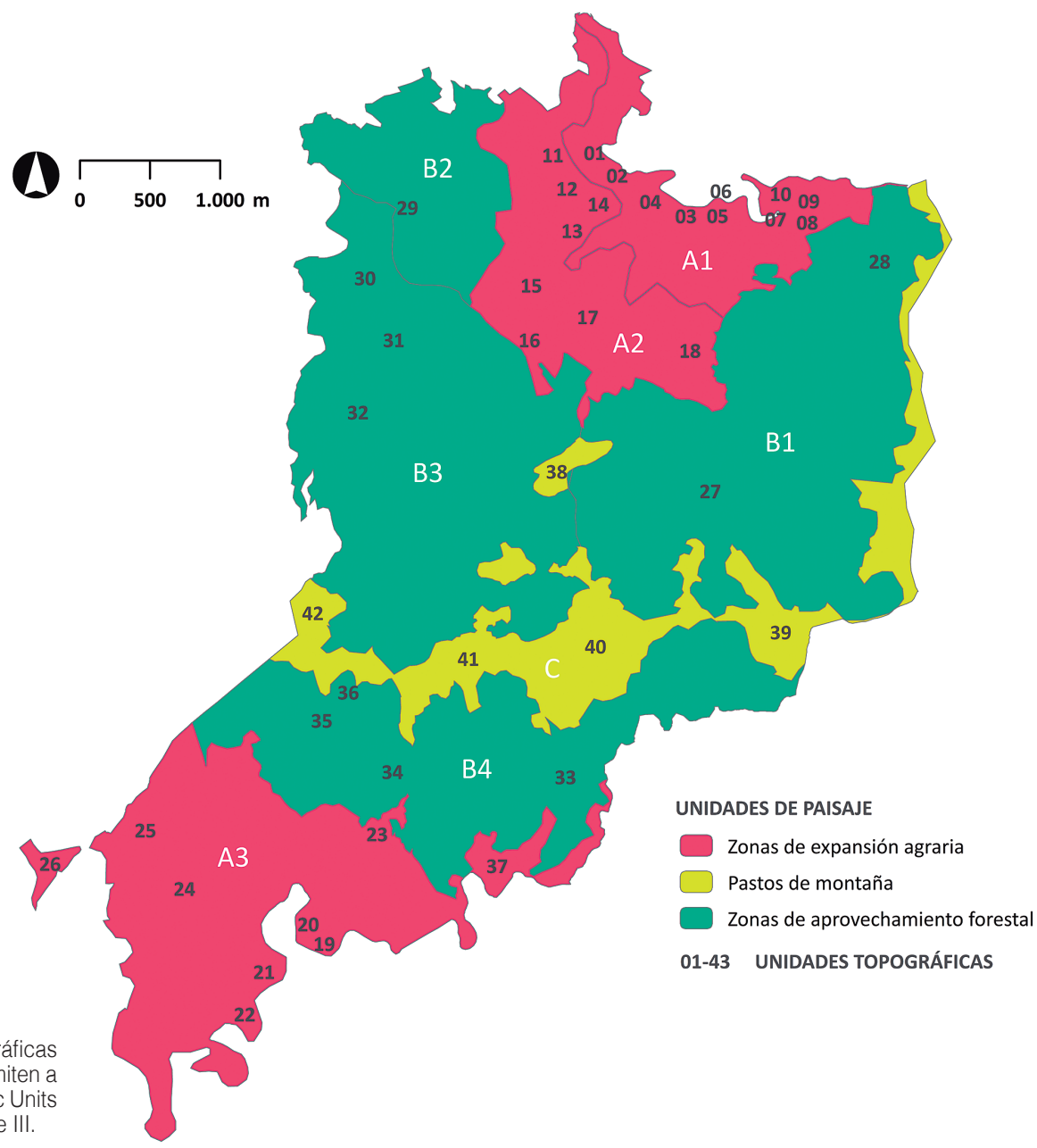

01-43 UNIDADES TOPOGRÁFICAS

\footnotetext{
${ }^{5}$ La geodatabase resultante del trabajo ha sido depositada en el Archivo del Centro de Patrimonio Cultural del Gobierno Vasco. Invitamos a cualquier persona interesada a consultar los datos en dicha sede.
} 


\begin{tabular}{|c|c|c|c|}
\hline Unidad de paisaje & Subunidad & Descripción & Unidades Topográficas \\
\hline \multirow{3}{*}{$\begin{array}{l}\text { A - Zonas de expansión agraria (100- } \\
\mathbf{5 0 0} \mathbf{~ m} \mathbf{~ s n m ) . ~} \\
\text { Caserío disperso asociado a cobertu- } \\
\text { ras diversificadas de tipo agropecua- } \\
\text { rio. Además de las propias viviendas, } \\
\text { documentan artefactos como establos, } \\
\text { caleras, setos y muros de piedra seca } \\
\text { para la parcelación de los campos }\end{array}$} & $\begin{array}{l}\text { A1 - Valle del río } \\
\text { Tornola }\end{array}$ & $\begin{array}{l}\text { Caserío disperso distribuido en la ladera } \\
\text { derecha del valle del río Tornola, hasta apro- } \\
\text { ximadamente } 400 \text { m de altitud. El río vertebra } \\
\text { esta subunidad, en cuyo cauce se constata } \\
\text { la presencia de infraestructuras hidráulicas. }\end{array}$ & $\begin{array}{l}\text { UT01 - Txarondo } \\
\text { UT02 - Portuberri } \\
\text { UT03 - Portuburu } \\
\text { UT04 - Lataborda } \\
\text { UT05 - Artxabaleta } \\
\text { UT06 - Sailpuru } \\
\text { UT07 - Baztekalte } \\
\text { UT08 - Intzentsoro } \\
\text { UT09 - Lorbide } \\
\text { UT10 - Olanditu }\end{array}$ \\
\hline & $\begin{array}{l}\mathrm{A} 2 \text { - Valle de la } \\
\text { regata Epele }\end{array}$ & $\begin{array}{l}\text { Prados y pastos, salpicados de asentamien- } \\
\text { tos dispersos formando barrios de bordas o } \\
\text { caseríos dispersos, intercalados con zonas } \\
\text { de bosque mixto y plantaciones forestales. }\end{array}$ & $\begin{array}{l}\text { UT11 - Bordaberri } \\
\text { UT12 - Añakadi } \\
\text { UT13 - Epele } \\
\text { UT14 - Karobizar } \\
\text { UT15 - Emieta } \\
\text { UT16 - Zaldirinzahar } \\
\text { UT17 - Madarimotx } \\
\text { UT18 - Penadegi }\end{array}$ \\
\hline & $\begin{array}{l}\text { A3 - Valle de } \\
\text { Añarbe }\end{array}$ & $\begin{array}{c}\text { Fondo de valle actualmente ocupado por la } \\
\text { cola del embalse del río Añarbe. Caseríos } \\
\text { dispersos intercalados con plantaciones y } \\
\text { bosques mixtos. }\end{array}$ & $\begin{array}{l}\text { UT19 - Okillegi } \\
\text { UT20 - Okillegitxiki } \\
\text { UT21 - Iraurgihandi } \\
\text { UT22 - Iraurgitxiki } \\
\text { UT23 - Gorosgarate } \\
\text { UT24 - Txaradi } \\
\text { UT25 - Larrazabal } \\
\text { UT26 - Añarbegoikoa }\end{array}$ \\
\hline \multirow{4}{*}{$\begin{array}{l}\text { B - Zonas de aprovechamiento fores- } \\
\text { tal (500-700 m snm). } \\
\text { Coberturas vegetales de tipo arbóreo: } \\
\text { plantaciones forestales, zonas de } \\
\text { rebrote de vegetación espontánea, } \\
\text { pequeñas manchas de pasto arbolado. } \\
\text { Los artefactos identificados reflejan, } \\
\text { sobre todo, usos ganaderos (biomar- } \\
\text { cadores liminales, muros de piedra } \\
\text { seca, árboles viejos trasmochos) y } \\
\text { forestales (carboneras), minería (bo- } \\
\text { caminas y puntos de carga) o, en los } \\
\text { cauces fluviales, aprovechamiento de } \\
\text { la energía hidráulica (presas y minicen- } \\
\text { trales hidroeléctricas). }\end{array}$} & $\begin{array}{l}\text { B1 - Cabecera del } \\
\text { río Tornola }\end{array}$ & $\begin{array}{l}\text { Laderas de media montaña predominante- } \\
\text { mente ocupadas por plantaciones forestales } \\
\text { y bosque mixto degradado. }\end{array}$ & $\begin{array}{l}\text { UT27 - Kosonegia } \\
\text { UT28 - Elorriko hegia }\end{array}$ \\
\hline & $\begin{array}{l}\text { B2 - Valle medio del } \\
\text { río Karrika }\end{array}$ & $\begin{array}{c}\text { Evidencias de actividad minera entre un } \\
\text { bosque mixto muy degradado y reemplaza- } \\
\text { do por plantaciones. }\end{array}$ & UT29 - Zorrola \\
\hline & $\begin{array}{l}\text { B3 - Cabecera del } \\
\text { río Karrika }\end{array}$ & $\begin{array}{l}\text { Laderas de media montaña predominante- } \\
\text { mente ocupadas por plantaciones forestales } \\
\text { y bosque mixto degradado. }\end{array}$ & $\begin{array}{c}\text { UT30 - Zorrolarezola Borda } \\
\text { UT31 - Ezkorrin } \\
\text { UT32 - Berin Zahar }\end{array}$ \\
\hline & B4 - Berdabio & $\begin{array}{l}\text { Laderas de media montaña predominante- } \\
\text { mente ocupadas por plantaciones forestales } \\
\text { y bosque mixto degradado, con presencia } \\
\text { de usos ganaderos abandonados. }\end{array}$ & $\begin{array}{l}\text { UT33 - Erarin } \\
\text { UT34 - Antonsoro } \\
\text { UT35 - Arizluzeta } \\
\text { UT36 - Larraundiborda } \\
\text { UT37 -Berdabio }\end{array}$ \\
\hline $\begin{array}{l}\text { C - Pastos de altura (700-900 m snm). } \\
\text { Pastos de montaña de carácter } \\
\text { herbáceo, con escasa vegetación } \\
\text { arbórea compuesta solo por pequeñas } \\
\text { manchas de hayedo trasmochado. }\end{array}$ & \multicolumn{2}{|c|}{$\begin{array}{c}\text { Cordal elevado que enlaza las cumbres de Zaria, } \\
\text { Kauso, Munagirre y Bianditz. }\end{array}$} & $\begin{array}{l}\text { UT38 - Oieleku } \\
\text { UT39 - Bianditz } \\
\text { UT40 - Munagirre } \\
\text { UT41 - Kausua } \\
\text { UT42 - Zaria }\end{array}$ \\
\hline
\end{tabular}

Tabla 3: Síntesis de las Unidades de Paisaje y Unidades Topográficas identificadas en Aiako Harria. / Summary of the Landscape Units and Topographic Units defined in Aiako Harria.

\section{DISCUSIÓN}

Cada una de las unidades identificadas permite leer sobre el terreno las huellas de una serie de prácticas cuya superposición en el espacio y en el tiempo ha contribuido a codificar la fisionomía actual del paisaje. Estas huellas encuentran su correlato en fuentes como la toponimia, los registros documentales o la memoria oral, que permiten abundar en el carácter históricamente construido del paisaje.

\subsection{Usos múltiples de la montaña en el Anti- guo Régimen (siglos XIII-XVIII)}

Hasta el siglo XIX, la principal forma de gestión de las superficies forestales en Aiako Harria fueron, como en la mayor parte de regiones montañosas europeas ${ }^{6}$, los pastos arbolados, espacios caracterizados por la convergencia de usos ganaderos y forestales. Estos usos se constatan documentalmente desde la Edad Media, mediante la definición de espacios de orienta-

\footnotetext{
${ }^{6}$ Existe una abundante literatura sobre esta cuestión, a partir del trabajo clásico de Rackham (1976) para Inglaterra. Algunos ejemplos significativos son Cevasco \& Molinari (2007) para los Apeninos, o Clément (2008) para las dehesas ibéricas. Para una reflexión general del sur de Europa en la larga duración, véase Stagno (2020). En el País Vasco, pueden consultarse los resultados del proyecto ARCHIMEDE en Aizkorri (Stagno et al., 2020).
} 
ción mixta como las bustalizas, los cubilares o los seles (Etxezarraga \& Aragón, 2020), que jugaron un papel relevante en la afirmación de ciertas élites laicas y eclesiásticas. Uno de los patrimonios más relevantes fue el de la Colegiata de Roncesvalles, que poseía desde el siglo XIII varias bustalizas en los vecinos montes de Errenga y Anizlarrea (Miranda, 1993; Díaz de Durana, 2001; Aragón, 2015). La colegiata firmó en 1389 y 1411 sendos tratados con los hidalgos locales del linaje de Ugarte, en torno a varios cubilares situados en el valle de Añarbe (Aragón, 2013; 2015). En sendas revisiones realizadas en 1508 y 1514, desaparecen las menciones de muchos de estos cubilares, pero aparecen citados varios seles, situados ahora en los valles de Tornola y Karrika, en manos de la Colegiata de Roncesvalles, de la encomienda de Zizur de la orden de San Juan de Rodas y de varios particulares locales (Aragón, 2013).

En contraste, entre los siglos XIV y XVI tuvo lugar un proceso de emancipación de las comunidades locales guipuzcoanas, que se esforzaron por recuperar espacios y aprovechamientos que les habían sido usurpados; hecho que, en el caso de Aiako Harria, se tradujo en una enajenación de los seles de Roncesvalles, mediante la donación en censo perpetuo de varios de ellos al concejo de Errenteria en 1521 y la venta de varios otros al de Oiartzun en 1571 (Aragón, 2013; 2015). Durante la Edad Moderna, la regulación y la gestión de estos espacios quedó en manos de las instituciones locales, que se vieron en la tesitura de conjugar sus intereses colectivos con los de otros actores sociales de escala local o regional (Aragón, 2009c). Así, a los usos ganaderos se superpusieron otros como el carboneo, fundamental para el sostenimiento de la industria ferrona local ${ }^{7}$, así como la construcción civil y naval, muy relevantes también debido a la cercanía de núcleos urbanos como Donostia, Errenteria u Hondarribia y de la industria naval alojada en la bahía de Pasaia (Odriozola, 2002).

La mayoría de los antiguos seles todavía pueden localizarse con facilidad, sobre todo en la unidad de paisaje B. Por un lado, la mayoría de los topónimos con los que los registros documentales se refieren a ellos sigue manteniendo su vigencia; por otro lado, muchos tienen también un reflejo material en el parcelario, al haberse conservado su morfología circular individualizada en el seno de los MUP, o al menos caracterizada por una cobertura vegetal distintiva. Un ejemplo claro es el sel de Berinzahar (UT32) ne de una borda arruinada, un cercado de piedra seca y varios biomarcadores liminales —endrinos (Prunus spinosa) y abedules (Betula pendula) —, todo ello asociado a un parcelario de morfología circular (Fig. 4a). El mismo fenómeno se observa en la vertiente meridional de Aiako Harria, en el sel de Erain (UT33) ${ }^{9}$; en este
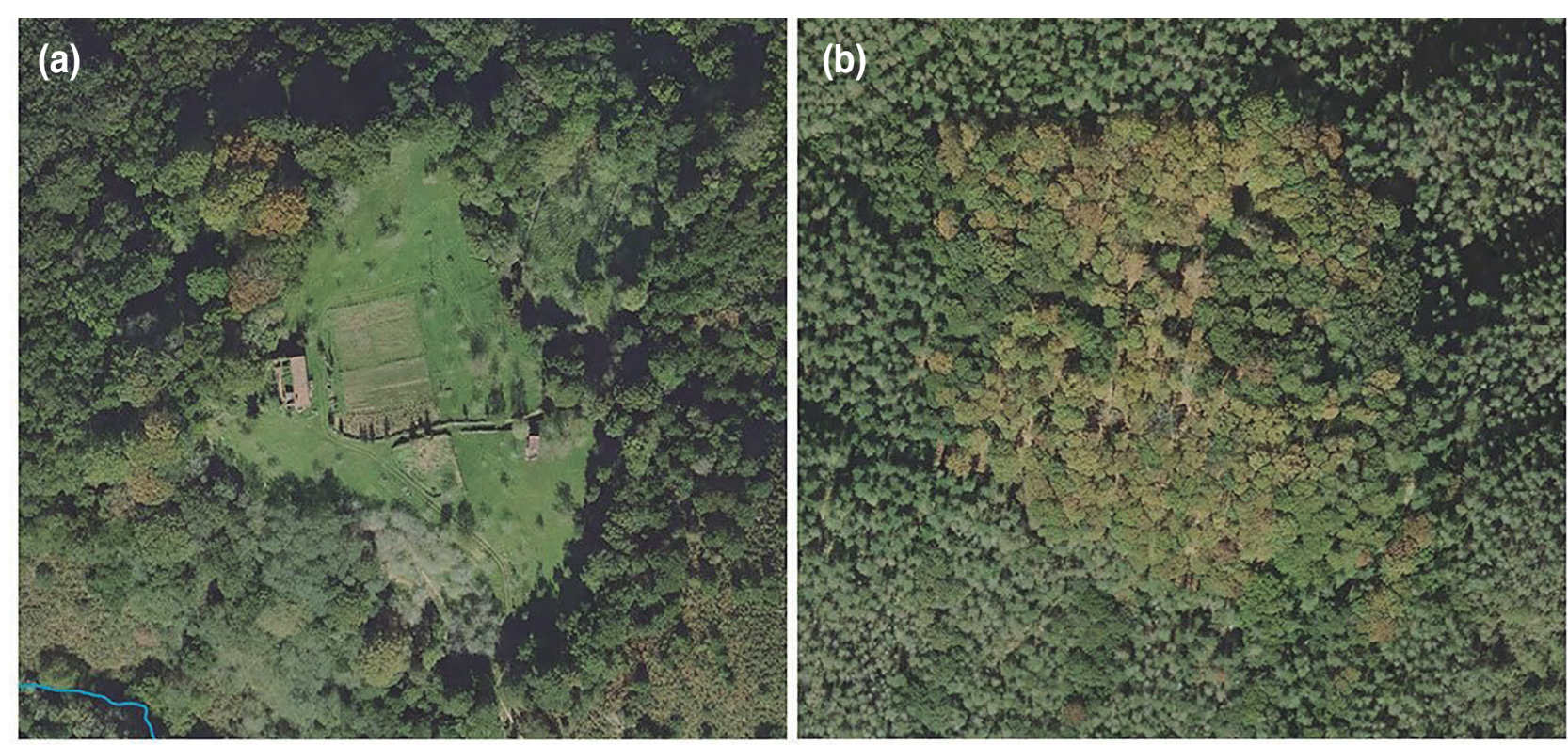

\section{$\Delta \prod_{0}^{10} \prod_{40 \mathrm{~m}}$}

$\boldsymbol{D}_{0}^{1} \overbrace{30}^{1} \quad 60 \mathrm{~m}$

Fig.4. (a) UT32 Berinzahar. (b) UT33 Erain.

\footnotetext{
${ }^{7}$ Así consta, ya en el siglo XIV, en el Pleito de los Ferrones que enfrentó a los dueños de las ferrerías de Irun y Oiartzun con las comunidades locales (Ayerbe Iríbar et al., 2012).

${ }^{8}$ La referencia más antigua corresponde a 1514, cuando el sel de Berin se cita como perteneciente a tres particulares locales (Aragón Ruano, 2013). ${ }^{9}$ Documentado desde 1514 como un espacio ganadero cuya propiedad era compartida entre la Colegiata de Roncesvalles y dos particulares (Aragón, 2013).
} 
caso, la morfología circular no ha quedado reflejada en el parcelario, ya que este entorno queda englobado dentro de los MUP, pero sí es claramente visible en las ortofotos históricas y actuales, al mantenerse unas coberturas terrestres diferenciadas dentro del sel plantación de roble americano- y fuera de él — pino laricio- (Fig. 4b).

Las trazas materiales documentadas tanto en el interior de los antiguos seles como en sus inmediaciones indican que, en el pasado, los aprovechamientos ganaderos y forestales convivían en los mismos formando pastos arbolados altamente intervenidos. Un ejemplo es el ya citado sel de Erain (UT33), donde se conservan, intercalados entre la moderna plantación de roble americano, algunos robles viejos trasmochos y los restos de una carbonera y de una borda (Fig. 5). Otro ejemplo se encuentra en Berdabio (UT37), donde se documentan varios ejemplares de marojo viejo trasmocho, asociados a la presencia de carboneras (Fig. 6). Tanto el marojo (Quercus pyrenaica) como el roble (Quercus robur) y el castaño (Castanea sativa) han sido árboles secu- larmente criados y trasmochados, cuyo manejo respondía a los fines específicos asignados a cada ejemplar (Aragon Ruano, 2001). Sin embargo, la presencia de este tipo de coberturas es testimonial en la actualidad, debido a la reducción de superficies forestales ante la expansión agraria o al aumento de la presión ganadera a lo largo de la época moderna; la expansión, a principios del siglo XX, de enfermedades como la tinta del castaño (Phytophthora sp.) (Goicoechea, 1900), o el oídio del roble (Microsphaera alphitoides) (Berriochoa, 2016); o la fuerte expansión de plantaciones forestales a lo largo del siglo XX.

Las evidencias de estos usos múltiples se documentan, más allá de los espacios históricamente delimitados como seles, en toda el área de estudio, lo que indica que su extensión fue en el pasado mucho más amplia de lo que las coberturas vegetales actuales podrían sugerir. El ejemplo más evidente son las carboneras —fácilmente identificables por su característica forma de terraplén y la presencia de fragmentos de carbón en superficie- que se encuentran en espacios
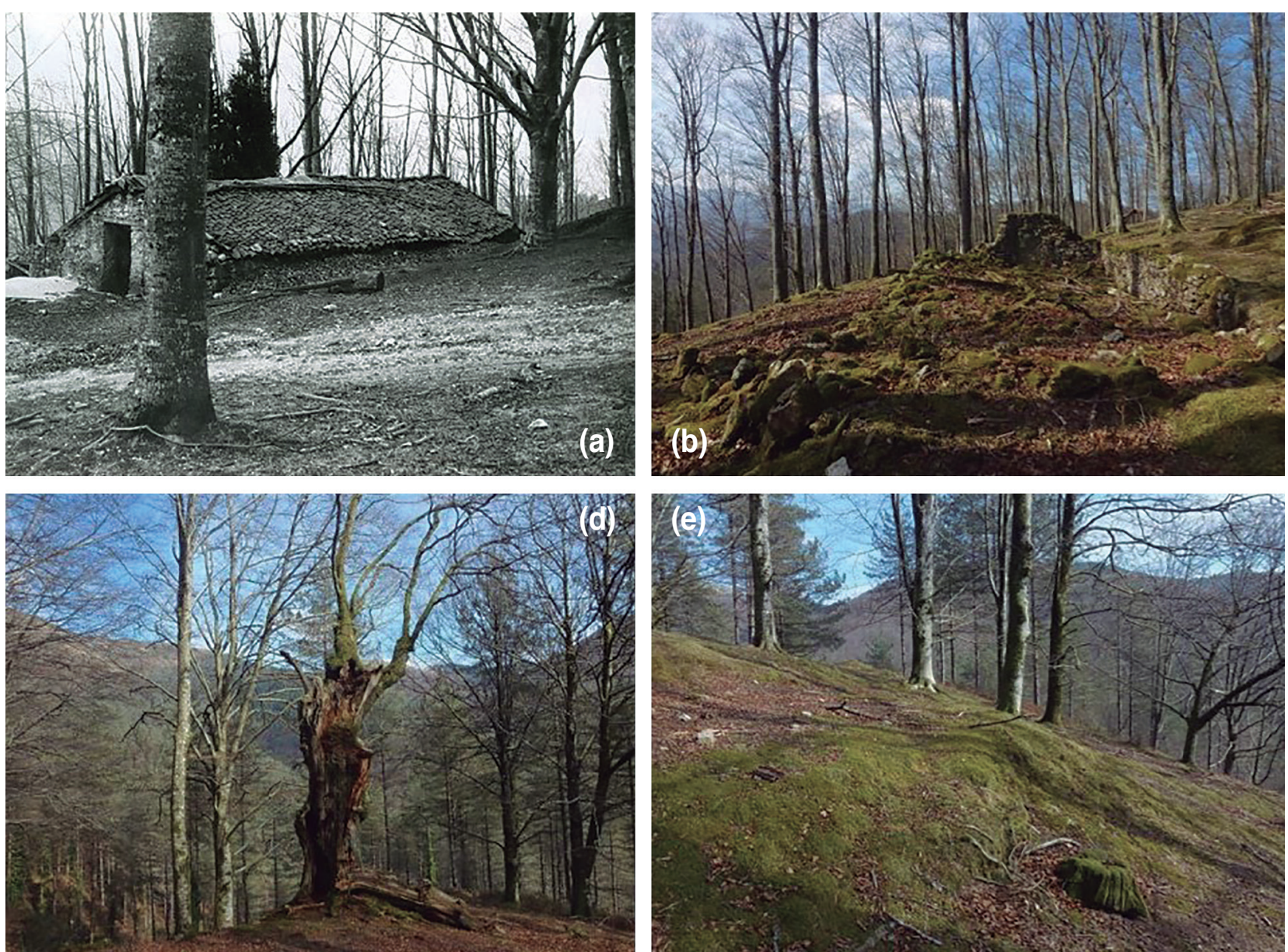

Fig.5. Elementos relacionados con usos ganaderos y forestales en el sel de Erain (UT33). (a) Borda, mediados del siglo XX. Fuente: oiartzuarrenbaitan.eus (consulta: 27/09/2018). (b) La misma estructura, en 2018. (d) Marojo viejo trasmocho. (e) Carbonera. / Husbandry- and forestry-related elements in the sel of Erain (TU33). (a) Hut, mid-20 ${ }^{\text {th }}$ century. Source: oiartzuarrenbaitan.eus (consulted on 27/09/2018). (b) The same structure, in 2018. (d) Old coppiced Pyrenean oak. (e) Charcoal pile. 

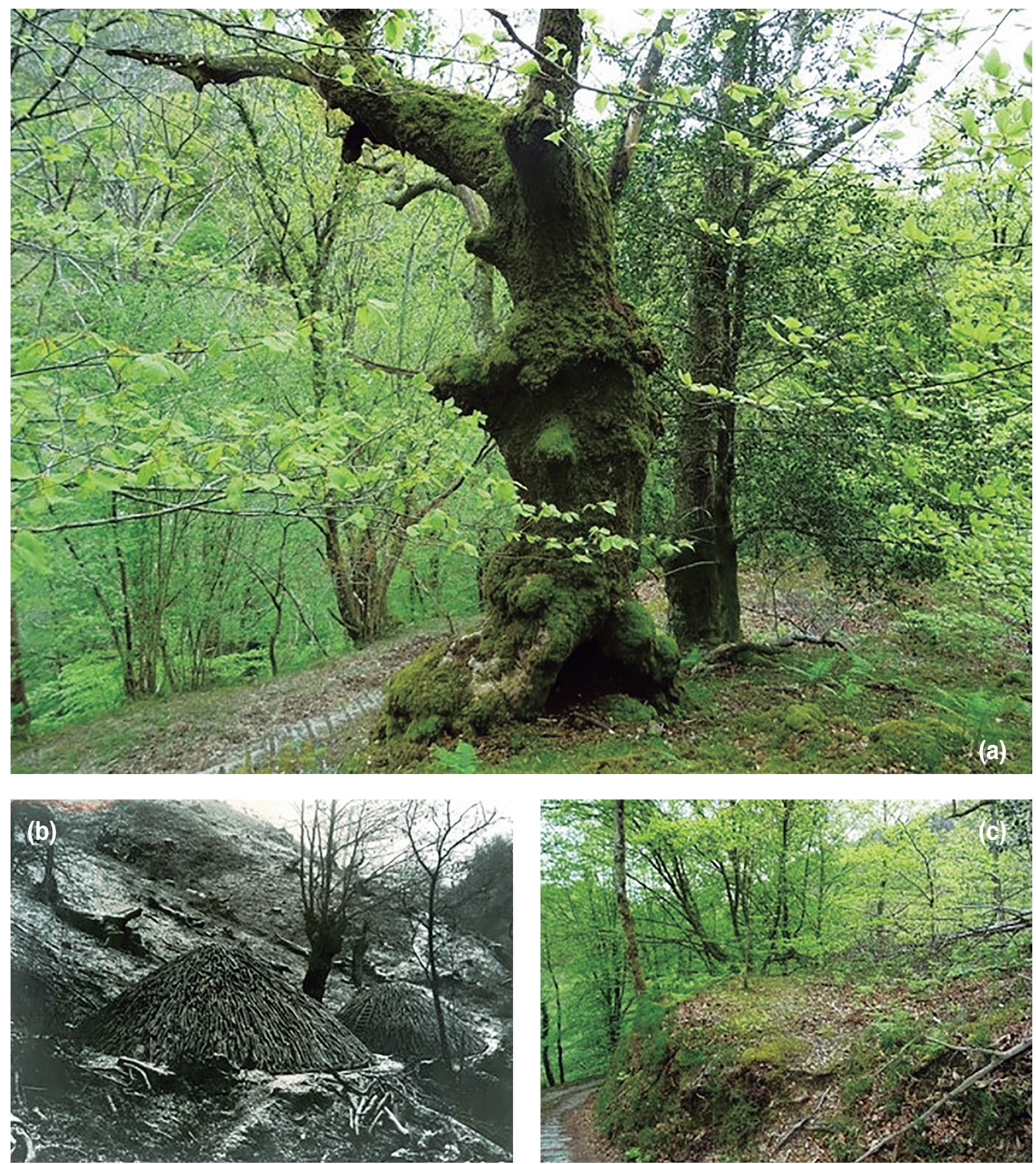

Fig.6. Berdabio (UT37). (a) Marojo viejo trasmocho. (b) Carboneras dispuestas para la combustión, a mediados del siglo XX. Fuente: oiartzuarrenbaitan.eus (consulta: 06-06-2020). (c) Restos de una carbonera de grandes dimensiones. / Berdabio (TU37). (a) Old coppiced Pyrenean oak. (b) Charcoal piles ready to be burnt, mid-20th century. Source: oiartzuarrenbaitan.eus (consulted on 06-06-2020). (c) Remains of a large charcoal pile.

actualmente ocupados por formaciones secundarias o, incluso, plantaciones forestales. La conservación de estos elementos es desigual y parece responder a la evolución de las coberturas terrestres y a los usos del suelo. La erosión es mayor en las zonas más escarpadas, especialmente bajo cubierta de abetos Douglas o similares. Por el contrario, bajo cubierta de coníferas, la presencia de helechos y zarzas cubre la superficie mitigando la erosión; un ejemplo de ello es la UT28, que abarca un amplio espacio forestal con más de un centenar de estructuras documentadas (Fig. 8). 
Otro tipo de cobertura relacionada con los pastos arbolados es el hayedo (Fagus sylvatica), un hábitat común en las montañas del norte peninsular (Olano \& Peralta de Andrés, 2009). Se documenta, sobre todo, en los cordales montanos situados por encima de los 700 $\mathrm{m}$ de altitud —unidad de paisaje C; Oieleku (UT38) ${ }^{10}$, Kauso (UT41) ${ }^{11}$ o Zaria (UT42) —, alternando con formaciones herbosas y brezales, dos hábitats relacionados con aprovechamientos ganaderos intensivos de base ovina (Ojeda, 2009; Rigueiro et al., 2009); aunque también en algunos puntos de los pisos altitudinales intermedios —unidad de paisaje B; Kosonegia (UT27)—, alternando con plantaciones forestales y formaciones secundarias de bosque mixto. El $85,3 \%$ de los hayedos prospectados muestra evidencias de haber sido trasmochado en el pasado (Fig. 7); un manejo cuya vigencia ha sido sugerida desde, al menos, el siglo XVIII (Aragón, 2001; 2009a; 2009b). La técnica más habitual era el trasmocho sin guiar, que la prospección ha per- mitido correlacionar con la existencia de carboneras en las inmediaciones. Las ramas de las hayas trasmochas eran cortadas regularmente, lo que permitía reiniciar su ciclo de crecimiento sin necesidad de tala. Los hayedos cumplían, así, una doble función al proporcionar leña para el carboneo al tiempo que servían como pastos arbolados. Esta relación entre el hayedo y los grupos sociales locales ha generado unos ecosistemas cultivados que llevan asociada una notable biodiversidad (Olalde \& Lizaso, 2007). Sin embargo, su poda regular ha sido abandonada, como muchos manejos tradicionales, desde mediados del siglo XX. Esto ha supuesto una ruptura en el ciclo de reproducción de estos árboles; las ramas situadas sobre el tronco principal han continuado creciendo, aumentando de grosor y acumulando cada vez más biomasa sobre el tronco principal. Su centro de gravedad se ha ido elevando progresivamente, con efectos negativos sobre su estabilidad y su resistencia frente al viento o la nieve ${ }^{12}$.

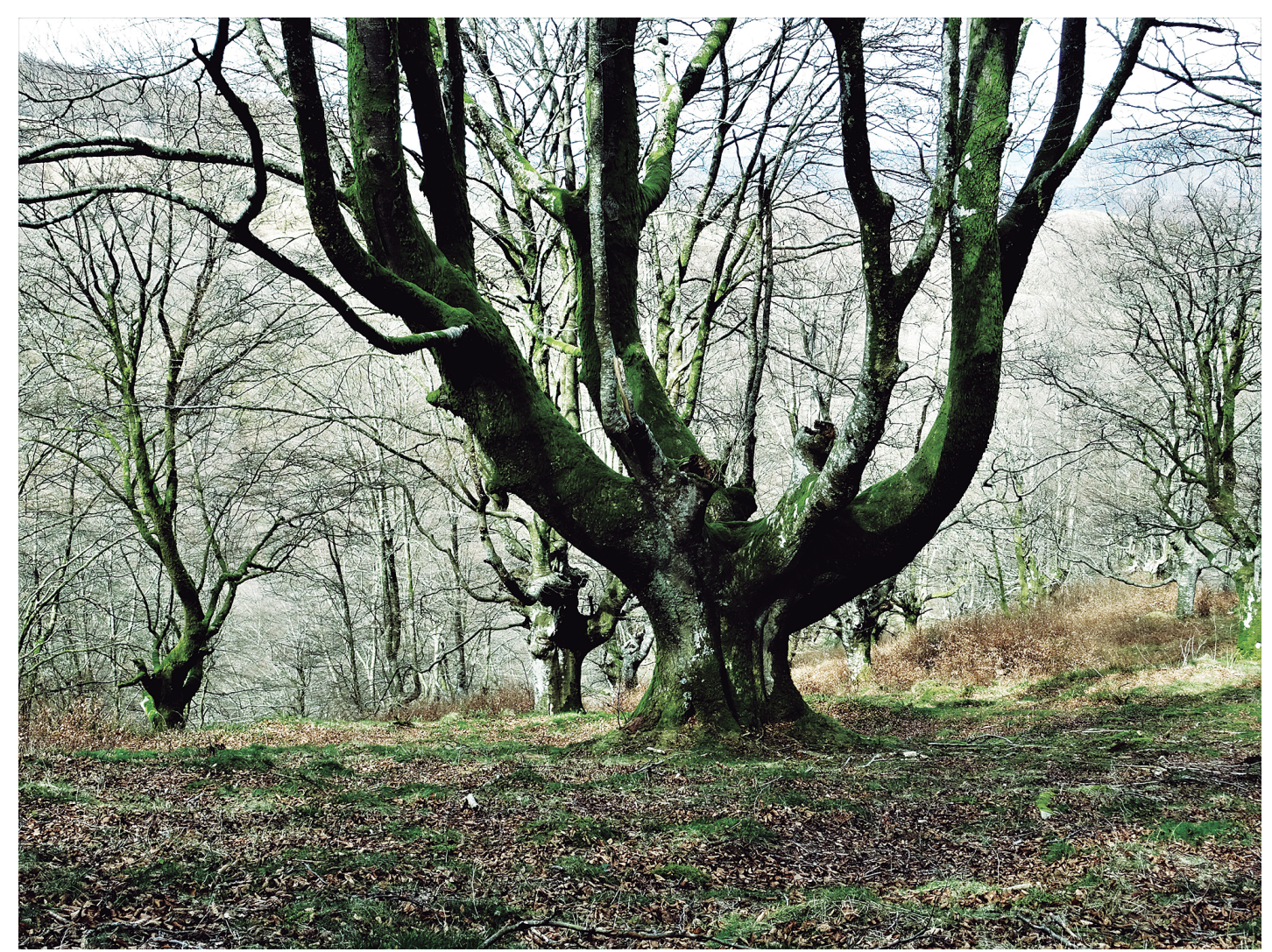

Fig.7. Hayedo trasmocho en Kosonegia (UT27). / Coppiced beech-forest in Kosonegia (TU27).

\footnotetext{
${ }^{10}$ Citado en 1514 como un sel perteneciente a dos particulares (Aragón, 2013).

${ }^{11}$ Citado en 1514 como un sel cuya propiedad era compartida entre la Colegiata de Roncesvalles y el señor Martín Martínez de Lastaola (Aragón, 2013).

${ }^{12}$ En este contexto, el proyecto LIFE Aiako Harria 2005-2009 (https://ec.europa.eu/environment/life/project/Projects/index.cfm?fuseaction=home.showFile\&rep=file\&fil=LIFE05_NAT_E_000067_AfterLIFE_ES.pdf) planteó una serie de actuaciones en favor de su recuperación y puesta en valor del ZEC Aiako Harria, complementado con un proyecto específico LIFE+ Biodiversidad y Trasmochos 2008-2014 (https://ec.europa.eu/ environment/life/project/Projects/index.cfm?fuseaction=home.showFile\&rep=file\&fil=LIFE08_NAT_E_000075_FTR_ES.pdf). Sin embargo, estos esfuerzos no han conseguido resolver el problema de una conservación práctica de los ejemplares trasmochos; en el entorno de Oianleku, por ejemplo, se registra una pérdida anual de 10 o 12 hayas por los motivos referidos.
} 


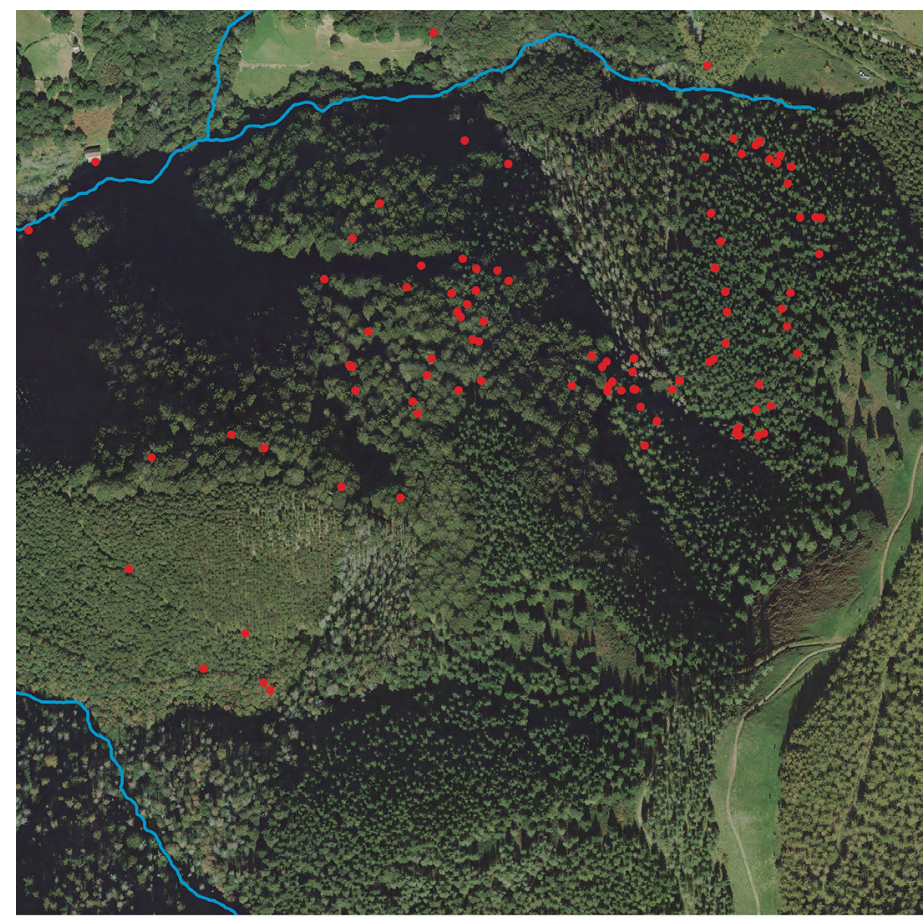

$\Delta \overbrace{0} \prod_{70}^{140 ~ m}$

Tras el abandono de los usos tradicionales, la mayor parte de los pastos arbolados se han visto sujetos a un proceso de asilvestramiento, en el que la falta de manejo ha propiciado un crecimiento de vegetación espontánea, dando lugar a la aparición de formaciones secundarias de bosque mixto. Un ejemplo de ello es el entorno de Zorrola (UT29), situado en un punto en el que el valle del Karrika se estrecha hasta quedar encajonado entre laderas abruptas. El elemento más reseñable es el puente de piedra de un solo arco, de cronología incierta, junto al que se conservan las bocas de una mina activa desde mediados del siglo XIX. En las inmediaciones se documentó, también, un muro de piedra seca asociado a varias hayas trasmochas, todas ellas sin guiar, en medio de una formación secundaria de bosque mixto. Aunque antiguamente existió aquí un sel ${ }^{13}$, resulta difícil delimitarlo atendiendo al parcelario y a las coberturas terrestres, un fenómeno que indudablemente debe haberse repetido en otros puntos.

\subsection{Expansión del caserío disperso (siglos XVI-XIX)}

Las actividades agropecuarias en el área de estudio se relacionan con la presencia de un caserío disperso (Fig. 9), asociado a explotaciones diversificadas de base doméstica, compuestas por una combinación variable de áreas de producción agraria - huertas, maizales y zonas de frutales con cultivo de manzanos,
Fig.8. UT28 Elorriko hegia. Los puntos rojos indican la presencia de carboneras abandonadas. / TU28 Elorriko hegia. Red dots indicate the presence of abandoned charcoal piles. perales o cerezos - y ganadera — prados, pastos cultivados y arbolados-, diseminados entre superficies forestales de titularidad pública o privada. Se trata de la cobertura predominante en la parte media del valle del río Tornola, y se encuentra presente, de manera más esporádica, en el valle de Añarbe. Los artefactos y estructuras documentados se relacionan, igualmente, con usos agrarios y ganaderos: nivelamientos, muros de contención y terraplenes que forman terrazas de cultivo; trincheras y canalizaciones orientadas a mitigar la erosión y asegurar el drenaje; caleras; setos, vallados y cerramientos de distintos tipos; frutales viejos. Todos estos elementos ponen de relieve el carácter diversificado e intensivo de dichas explotaciones en el pasado, en contraste con su actual declive.

Un ejemplo es la UT01, articulada en torno al caserío Txarondo (Fig. 10a). Este se sitúa sobre el río Tornola, en una zona umbría orientada al oeste. Bajo el edificio se encuentran los restos de un conjunto de terrazas de cultivo construidas con muros de piedra seca, reforzadas en algunos puntos con avellanos, en las que se conservan algunos manzanos viejos en estado de abandono. En el extremo septentrional de la UT, junto al río, se encuentra el molino Txarondoerrota, y junto a este un cercado de piedra seca y varios castaños viejos. Toda la zona está rodeada de bosques mixtos degradados, compuestos por vegetación arbórea y arbustiva espontánea, sin evidencias de manejo.

${ }^{13}$ El topónimo se documenta en 1411 como un sel perteneciente a dos particulares (Aragón, 2013). 


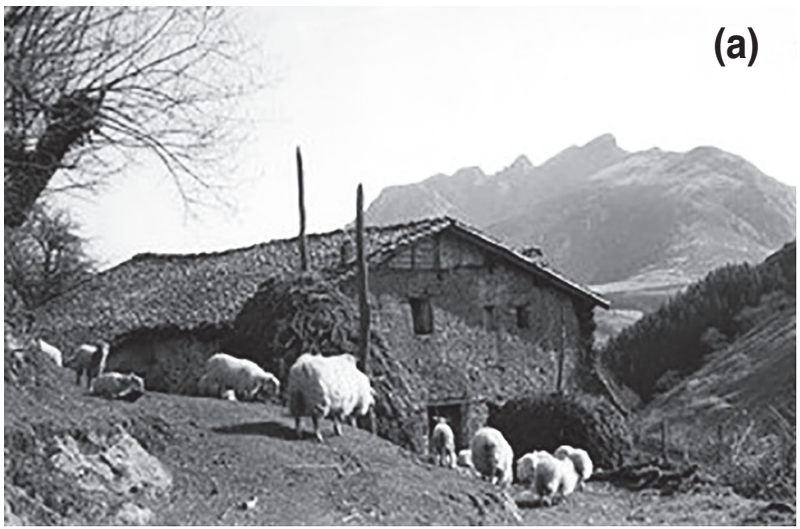

(c)

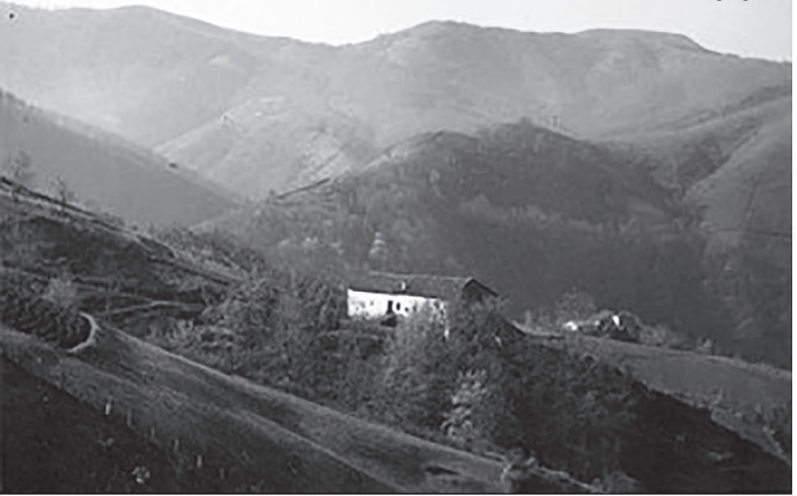

(e)

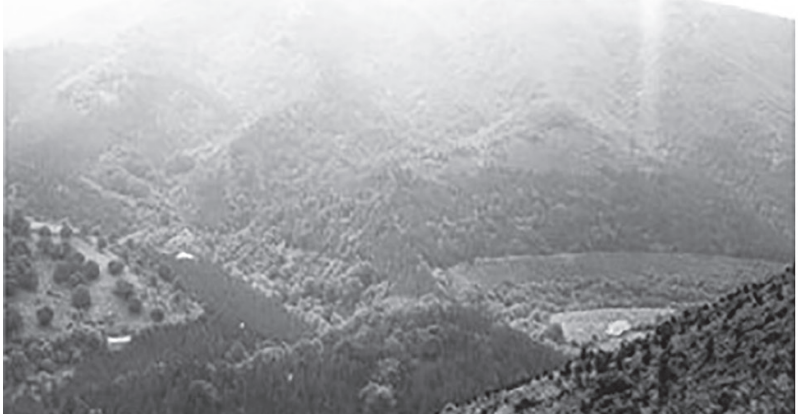

Fig.9. Ejemplos de caseríos construidos sobre antiguos espacios de dedicación ganadera y forestal, bordas y seles. (a) Emieta (UT15). (b) Berinzahar (UT32). (c) Portuburu (UT03) y Tomasenborda. (d) Bazterkalte (UT07). (e) Okillegi (UT19), Okillegitxiki (UT20) e Iraurgi (UT21 \& UT22). (f) Txaradi (UT24). Fuente: oiartzuarrenbaitan .eus (consulta: 06/06/2020). / Examples of farmhouses built on former pasture areas (bordas and seles). (a) Emieta (TU15). (b) Berinzahar (TU32). (c) Portuburu (TU03) and Tomasenborda. (d) Bazterkalte (TU07). (e) Okillegi (TU19), Okillegitxiki (TU20) and Iraurgi (TU21 \& TU22). (f) Txaradi (TU 24). Source: oiartzuarrenbaitan.eus (consulted on 06/06/2020).

Txarondo es el primero de una serie de caseríos que jalonan el camino que asciende hacia el collado de Aritxulegi: Portuberri (UT02), Portuburu (UT03), Lataborda (UT04), Artxabaleta (UT05), Sailpuru (UT06), Bazterkalte (UT07), Intzentsoro (UT08), Lorbide (UT09) y Olanditu (UT10). Forman una agrupación o barrio de carácter disperso, actualmente atravesado por la carretera que une Oiartzun con la localidad navarra de
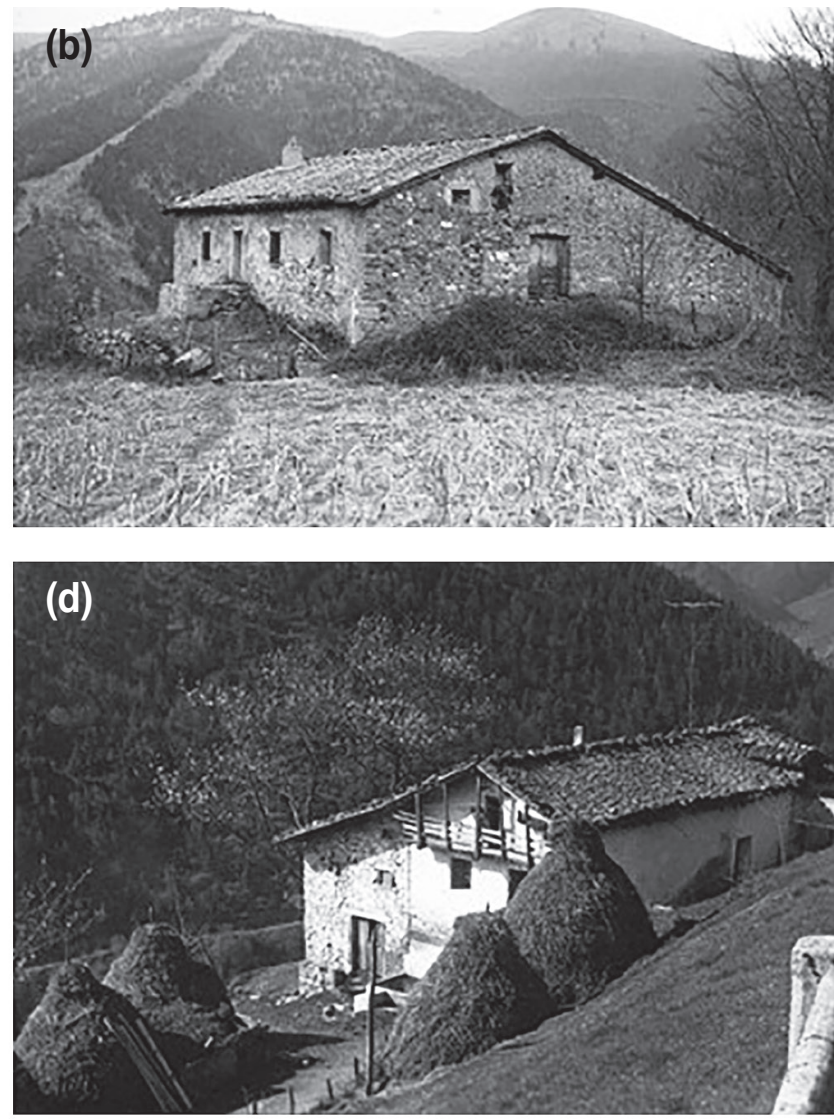

(f)

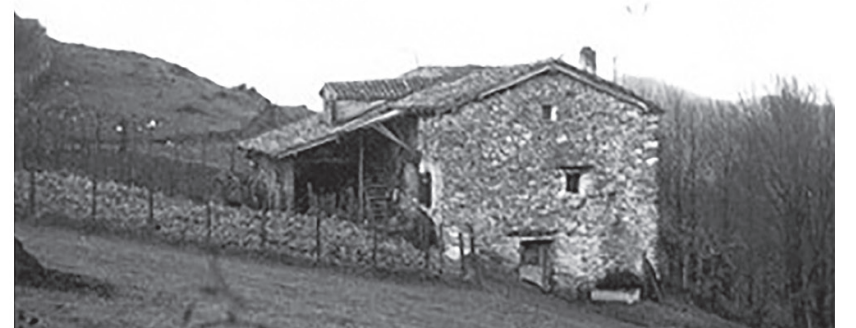

Lesaka, pero que estuvo antiguamente interconectado por una red de caminos de los que quedan algunos restos. Existen registros documentales que indican que al menos Olanditu acogía un sel a finales de la Edad Media $^{14}$, lo que, unido a una toponimia que remite a usos de tipo ganadero (borda, ola, portu) y forestal (Iorbide, txaro), apunta a una reorientación agraria de estos espacios en época moderna.

${ }^{14}$ Citado en 1514 como perteneciente a la orden de San Juan de Rodas (Aragón, 2013). 
Otro ejemplo es la UT15, que tiene como eje el caserío Emieta, rodeado de huertas, prados cultivados y algunas parcelas de frutales, con setos y muros de piedra seca construidos como límites parcelarios. La microtoponimia abunda en el carácter diversificado de los usos del suelo, con referencias a la fruticultura (Bimadarieta), al pasto (Emietalarre) o a la recogida de helechos para la fabricación de estiércol (Emietako iratzea). Todo ello se asocia a un parcelario claramente circular, que remite al antiguo uso de este espacio como sel ${ }^{15}$. También Emieta forma parte de un conjunto de caseríos dispersos situados, en este caso, en las laderas que desde la antigua casa-torre de Pagoaga ascienden hacia el puerto de Basate: Bordaberri (UT11), Añakadi (UT12), Epele (UT13), Karobizar (UT14), Zaldirinzahar (UT16), Madarimotx (UT17), Penadegi (UT18).

La dispersión del caserío se acentúa en la vertiente meridional de Aiako Harria. El caserío Gorosgarate (UT23), por ejemplo, se sitúa en un pequeño rellano en la ladera del monte Zaria (Fig. 10b). El conjunto forma un parcelario circular, rodeado de unos MUP consistentes sobre todo en plantaciones forestales, aunque existen algunos restos de hayedo y marojal trasmocho. La disposición espacial del caserío Gorosgarate es sin duda el reflejo de un uso anterior como sel, acreditado documentalmente ${ }^{16}$. Otras UT similares son Okillegi (UT19), Okillegitxiki (UT20), Iraurgihandi (UT21), Iraurgitxiki (UT22), Txaradi (UT24), Larrazabal (UT25) y Añar- begoikoa (UT26). Muchos de ellos constan como antiguos seles: sendos registros de 1389 y 1411 indican que la Colegiata de Roncesvalles poseía, entre otros, los seles de Okillegi de suso y de yuso, Iraurgi de suso y de yuso, y Añarbe; en 1411 se cita, también, el de Txaradi; sin embargo, en 1514 solo se mencionan los de Okillegi, Iraurgi de suso y de yuso (Aragón, 2013), lo que podría indicar que el proceso de conversión de estos seles en caseríos se encontraba ya en marcha a principios del siglo XVI.

Estos espacios encajan en el proceso de expansión de las superficies agrarias en época moderna, documentada en todo el País Vasco tras la introducción de especies americanas, como el maíz, y la roturación de espacios situados en la periferia de los hábitats de origen medieval (p.ej., Bilbao \& Fernández de Pinedo, 1984; Aragón, 2015). Tal expansión se produjo, en particular, sobre espacios montanos que habían tenido antes una dedicación ganadera y forestal, especialmente sobre aquellos que, como los seles, constituían ya entidades espaciales bien definidas. Este proceso generó un cambio en la estructura de los hábitats rurales del territorio, con la formación de un caserío cada vez más disperso y atomizado y una progresiva desarticulación de las formas de gestión colectiva (Narbarte, 2020; Narbarte et al., 2020), lo que eventualmente puso las bases para la transformación radical que estos espacios iban a sufrir a partir del siglo XIX.
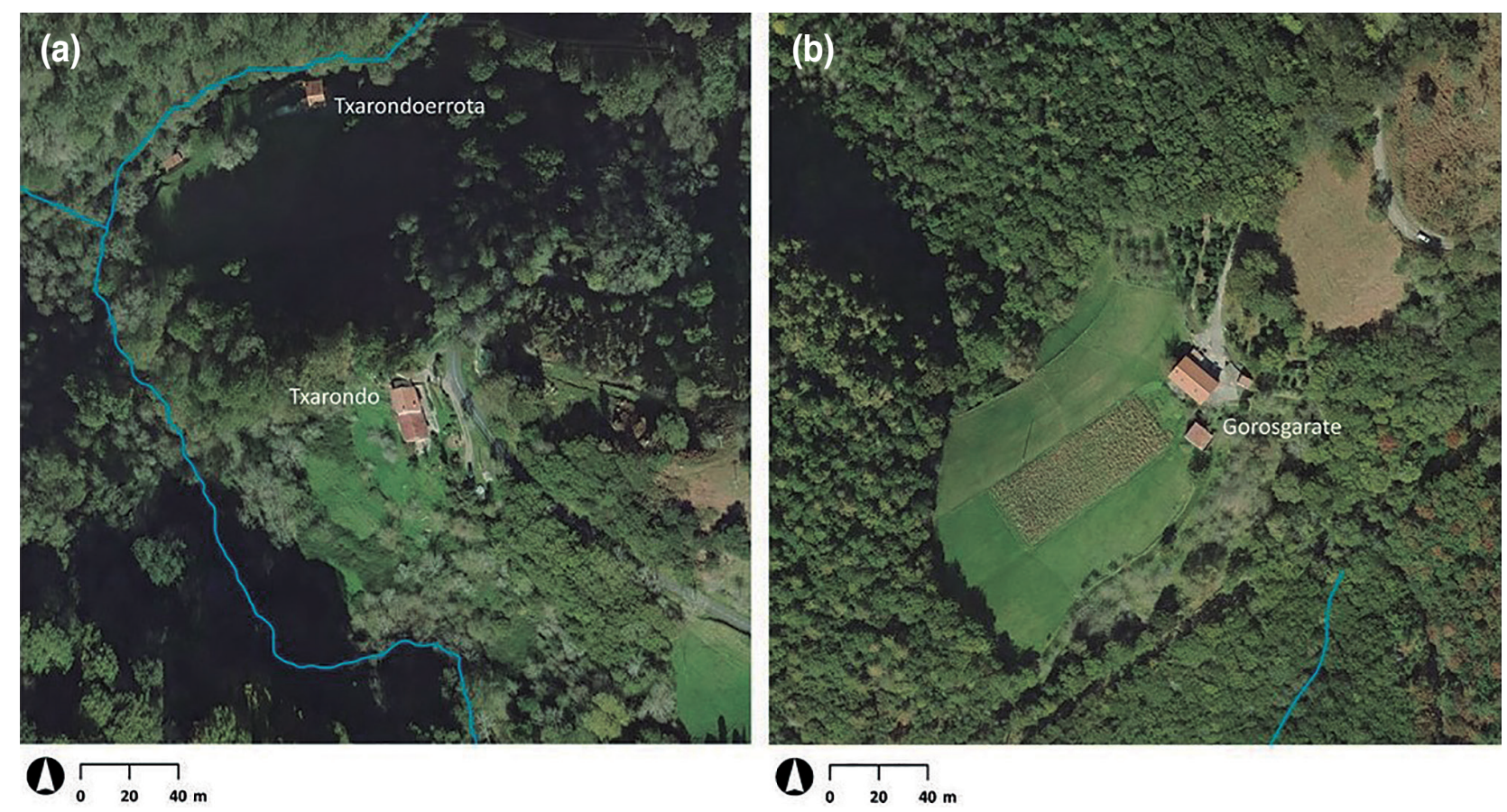

Fig.10. (a) UT01 Txarondo. (b) UT23 Gorosgarate.

\footnotetext{
${ }^{15}$ Citado en 1514 como perteneciente a la orden de San Juan de Rodas (Aragón, 2013).

${ }^{16}$ En 1514, el topónimo aparece citado como un sel en manos de la Colegiata de Roncesvalles y dos particulares (Aragón, 2013).
} 


\subsection{Predominio de las plantaciones foresta- les (siglos XIX-XX)}

Las plantaciones forestales son actualmente la principal cobertura presente en Aiako Harria; aunque su peso relativo es inferior al que alcanzan en comarcas vecinas, suponen cerca de la mitad de la superficie forestal (878,7 ha), distribuidas entre 200 y $500 \mathrm{~m}$ de altitud y compuestas por especies alóctonas de crecimiento rápido. Estas especies se asocian a un tipo de explotación forestal intensiva que implica el empleo de maquinaria pesada y la apertura de pistas y matarrasas, lo que podría explicar la casi total ausencia de trazas de actividades anteriores.

Estos espacios reflejan un proceso de intensificación de las actividades forestales desde finales del siglo XIX, en un escenario de industrialización de la sociedad y tecnificación del medio rural, que desembocó en una pérdida efectiva de personas, usos y manejos. De manera similar a lo sucedido en el resto de Gipuzkoa, la introducción de estas especies se operó en un contexto de fuerte degradación de los montes preindustriales (Michel \& Gil, 2013). La especie que se introdujo con más fuerza fue inicialmente el pino insigne (Pinus radiata), cuya expansión se vio frenada por las heladas de 1956 dando lugar a una posterior diversificación - pino laricio (Pinus nigra), alerce (Larix kaempferi) o abeto Douglas (Pseudotsuga menziesii). La gran extensión que abarca este tipo de coberturas lleva ya décadas planteando cuestiones sobre su gestión; en 2007 se estimaba que el 16\% de los MUP eran plantaciones maduras que habían llegado a su turno de corta o estaban muy próximas (Olalde Fernández \& Lizaso Sánchez, 2007), lo que planteaba la incógnita de su dedicación futura. Una cuestión que vuelve a estar encima de la mesa tras la crisis provocada por la propagación, desde 2017, de la banda marrón (Lecanosticta acicola), un hongo que ha afectado gravemente a gran parte de las plantaciones del territorio (Mesanza et al., 2019; Van der Nest et al., 2019).

\section{CONCLUSIÓN}

El trabajo desarrollado en Aiako Harria pone de relieve el potencial de una estrategia de prospección, basada en una base de datos georreferenciada, a la hora de generar información relevante sobre la historia de los usos del suelo y la evolución del paisaje de montaña. Los resultados obtenidos reflejan una gran pluralidad de prácticas y procesos que se cruzan en el espacio de manera estratificada, dejando diversas huellas materiales que forman, a su vez, unidades espaciales características. En este sentido, la Unidad de Paisaje y la Unidad Topográfica se han revelado como herramientas analíticas válidas para abordar estas cuestiones desde un punto de vista comparativo, permitiendo además integrar eficazmente la información obtenida de la prospección con la proveniente de registros documentales, orales o toponímicos.
Desde el punto de vista de las prácticas de gestión de los recursos, en Aiako Harria predominan en la actualidad las plantaciones forestales de vocación industrial, que se expandieron durante el siglo XX sobre superficies cada vez más extensas. Estas plantaciones se han superpuesto a los usos múltiples que anteriormente caracterizaron la gestión de estos espacios. Entre estos, destacan los pastos arbolados, a menudo gestionados mediante técnicas como el trasmocho, cuyas trazas aún son visibles sobre el terreno. Las evidencias documentales de tales prácticas se remontan a la Edad Media, y han ido evolucionando hasta generar espacios especializados como los seles. A su vez, muchos de estos espacios fueron transformándose durante la época moderna en caseríos asociados a explotaciones agropecuarias diversificadas, formando nuevos hábitats dispersos en las laderas bajas de Aiako Harria.

Ahora bien, las relaciones entre personas y aprovechamiento de los recursos se han ido difuminando en las últimas décadas, como consecuencia de los cambios socioeconómicos acontecidos a escala local, regional y global. Así, al abandono de las economías campesinas de base doméstica y de las formas de aprovechamiento que habían contribuido a mantener y reproducir el ecosistema cultivado de Aiako Harria, se suma la introducción de nuevos manejos de carácter intensivo y especializado; todo ello ha supuesto un profundo impacto en el paisaje local que, lejos de quedar congelado, ha seguido en continua transformación, planteando nuevos retos para su gestión.

Así, frente a la aparente ilegibilidad de unos espacios a menudo abordados desde un prisma puramente naturalístico, los resultados alcanzados muestran el potencial de la arqueología para aprehender la densidad histórica de los paisajes de montaña. La superposición de usos y relaciones a lo largo del tiempo no solo deja huellas sobre el terreno, sino que éstas establecen entre sí relaciones espaciales y estratigráficas que permiten leer los patrones de continuidad o ruptura que pudieron darse en el pasado. De este modo, es posible identificar y evaluar las formas de gestión que han contribuido a una reproducción sostenible de los ecosistemas ligados a estos paisajes, proporcionando también una mayor precisión a la ordenación territorial a la hora de definir y gestionar las correspondientes figuras de actuación a escala local o regional.

\section{AGRADECIMIENTOS}

Este trabajo es el resultado del proyecto "Pasado y Presente del Paisaje Cultural de Montaña en la CAPV: desarrollo metodológico para el estudio arqueológico y puesta en valor de los espacios de bosque y pasto", financiado por el Departamento de Cultura y Política Lingüística del Gobierno Vasco (2017-2018). Los autores agradecen su colaboración a Ainara Lasa, que ha participado en el trabajo de campo, así como a Anna Maria Stagno y a dos revisores anónimos, por las aportaciones realizadas para mejorar el texto final. 


\section{BIBLIOGRAFÍA}

Aragón Ruano, Á., 2001. El bosque guipuzcoano en la Edad Moderna: aprovechamiento, ordenamiento legal y conflictividad. Aranzadi Zientzia Elkartea, Donostia.

Aragón Ruano, Á., 2009a. Una longeva técnica forestal: los trasmochos o desmochos guiados en Guipúzcoa durante la Edad Moderna. Espacio, Tiempo y Forma (Serie IV, Historia Moderna) 22, 73-105.

Aragón Ruano, Á. 2009b. Los Robles Trasmochos Guiados o Ipinibarros: una apuesta sostenible de futuro para una técnica forestal olvidada. Actas de la III Reunión sobre Historia Forestal. Cuadernos de la Sociedad Española de Ciencias Forestales 30, 137-142.

Aragón Ruano, Á., 2009c. La ganadería guipuzcoana durante el Antiguo Régimen. UPV/EHU, Bilbao.

Aragón Ruano, Á., 2013. La ganadería en Oiartzun hasta comienzos del siglo XX. Oiartzungo Udala, Oiartzun

Aragón Ruano, Á., 2015. Relaciones ganaderas entre Navarra y Guipúzcoa durante la Baja Edad Media y el comienzo de la Edad Moderna. En la España Medieval 38, 13-35.

Ayerbe Iríbar, MªR., Irijoa Cortés, I., San Miguel Osaba, A., 2012. Documentación medieval del Archivo Municipal de Oiartzun.II. Pleito de los ferrones (1328-1514). Eusko Ikaskuntza, Donostia.

Bal, M.C., Rendu, C., Ruas, M.P., Campmajo, P., 2010. Paleosolcharcoal: Reconstructing vegetation history in relation to agro-pastoral activities since the Neolithic. A case study in the Eastern French Pyrenees. Journal of Archaeological Science 37, 1785-1797.

Berriochoa Azcárate, P., 2016. El bosque de Gipuzkoa entre los siglos XVIII y XX: deforestación y cambio de especies. Estudios Rurales 6, 11-31.

Braudel, F., 1949. La Méditerranée et le Monde Méditerranéen a l'époque de Philippe II. Armand Colin, Paris.

Calvet-Mir, L., Gómez-Baggethun, E., Reyes-García, V., 2012. Beyond food production: Ecosystem services provided by home gardens. A case study in Vall Fosca, Catalan Pyrenees, Northeastern Spain. Ecological Economics 74, 153-160.

Cevasco, R., 2007. Memoria Verde. Nuovi spazi per la geografía. Diabasis, Reggio nell'Emilia.

Cevasco, R., Molinari, C., 2007. Microanalysis in Woodland Historical Ecology. Evidences of past leaf fodder production in NW Apennines (Italy). Proceedings of the conference Woodland cultures in time and space: tales from the past, messages for the future, Thessaloniki (Greece), 3-7 September 2007. Embryo Publications, Atenas.

Del Amo Jiménez, E., Narbarte, J., 2018. Lejos del caserío. De la idealización a la (re)construcción del medio rural en la Euskal Herria atlántica. Actas del VII Congreso Internacional de Agroecología (Córdoba, 30 y 31 de mayo y 1 de junio de 2018), 949-957.

EHAA, 105, 1995-06-05. DECRETO 241/1995 de 11 de abril, por el que se declara Parque Natural el área de Aiako Harria.

EHAA, 81, 2002-05-02. DECRETO 87/2002 de 16 de abril, por el que se aprueba la parte normativa del Plan Rector de Uso y Gestión (PRUG) del Parque Natural de Aiako Harria.

EHAA, 224, 2013-11-25. DECRETO 355/2013, de 4 de junio, por el que se designa la Zona Especial de Conservación Aiako harria (ES2120016) y se aprueban sus medidas de conservación.
Díaz de Durana, J.R., 2001. Para una historia del monte y del bosque en la Guipúzcoa bajomedieval: Ios seles. Titularidad, formas de cesión y de explotación. Anuario de Estudios Medievales 31.1, 49-73.

Díez de Salazar, L. M. 1997. Ferrerías guipuzcoanas. Aspectos socioeconómicos, laborales y fiscales (siglos XIV-XVI). Kutxa, Donostia.

Etxezarraga Ortuondo, I., Aragón Ruano, Á., 2020. Entre la explotación pastoril y la forestal. La evolución en el uso y aprovechamiento de los seles en el País Vasco. Grau-Sologestoa, I., Quirós-Castillo, J.A. (eds.), Arqueología de la Edad Moderna en el País Vasco y su entorno, 123-139. Archaeopress, Oxford.

EVE, 1995. Minihidráulica en el País Vasco. EVE, Bilbao.

Falque-Vert, H. 1997. Les Hommes et la Montagne en Dauphiné au XIII siècle. Presses Universitaires de Grenoble, Grenoble.

Galop, D., Houet, T., Mazier, F., Laveux, G., Rius, D., 2011. Grazing activities and biodiversity history in the Pyrenees. New insights on high altitude ecosystems in the framework of a Human-Environment Observatory. Pages News 19(2), 53-55.

Gassiot, E., 2016. Montañas humanizadas. Arqueología del pastoralismo en el Parque Nacional d'Aigüestortes i Estany de Sant Maurici. Organismo Autónomo de Parques Nacionales, Madrid.

Gassiot, E., Pèlachs, A., 2017. La ocupación ganadera de los Pirineos occidentales de Catalunya en época romana e inicios de la Edad Media. Treballs d'Arqueologia 21, 287-306.

Gattiglia, G., Stagno, A., 2015. La documentazione scritta nella ricognizione archeologica sul territorio: un "vecchio" sistema di schedatura. Archeologia medievale 32, 453-460.

Gragson, T.L., Coughlan, M.R., Leigh, D.S., 2020. Contigency and Agency in the Mountain Landscapes of the Western Pyrenees: A Place-Based Approach to the Long Anthropocene. Sustainability 12, 3882.

Gragson, T.L., Leigh, D.S., Coughlan, M.R., 2015. Basque Cultural Landscapes of the Western French Pyrenees. II capitale culturale 12, 565-596.

Guadilla-Sáez, S., Pardo de Santayana, M., Reyes-García, V., 2019. The role of traditional management practices in shaping a diverse habitat mosaic in a mountain region of Northern Spain. Land Use Policy 89, 104-235.

Guadilla-Sáez, S., Pardo de Santayana, M., Reyes-García, V., 2020. Forest commons, traditional community ownership and ecological consequences: Insights from Spain. Forest Policy and Economics 112, 102-107.

Hazi Fundazioa, 2014. Apuntes sobre trasmochos. Guía de buenas prácticas para el trasmocheo. Gipuzkoako Foru Aldundia, Donostia.

Hernández Morcillo, M., Hoberg, J., Oteros-Rozas, E., Plieninger, T., Gómez-Baggethun, E., Reyes-García, V., 2015. Traditional Ecological Knowledge in Europe: Status Quo and Insights for the Environmental Policy Agenda. Environment: Science and Policy for Sustainable Development 56.1, 3-17.

Martínez Montecelo, Á., 2020. Arqueología en el Saltus: Nuevas perspectivas de investigación en ámbitos montanos y densamente forestados. Grau-Sologestoa, I., Quirós-Castillo, J.A. (eds.), Arqueología de la Edad Moderna en el País Vasco y su entorno, 182-193. Archaeopress, Oxford.

Mesanza, N., Raposo, R., Elvira-Recuenco, M., Hernández-Escribano, L., Barnes, I., van der Nest, A., Pascual, MT., Barrena, I., San Martín, U., Cantero, A., Iturritxa, E., 2019. New hosts for Lecanosticta acicola and Dothistroma septosporum in Spain. Preprints 2019, 2019120031, doi: 10.20944/preprints201912.0031.v1 
Miranda García, F., 1993. Roncesvalles. Trayectoria patrimonial (siglos XII-XIX). Nafarroako Gobernua, Iruñea.

Molina, M., Reyes-García, V., Pardo de Santayana, M., 2009. Local Knowledge and Management of the Royal Fern (Osmunda regalis L.) in Northern Spain: Implications for Biodiversity Conservation. American Fern Journal 99, 45-55.

Moreno, D., 1990. Dal documento al terreno. Storia e archeologia dei sistemi agro-silvo-pastorali. II Mulino-Ricerche, Bologna.

Mujika, J.A., Moraza, A., Moro Deordal, I., 2003. Contribución al estudio de las estructuras tumulares en arqueología: entre la similitud morfológica y la disparidad de funciones. Veleia 20, 243-272.

Mujika, J.A., Moraza, A., 2005. Establecimientos de habitación al aire libre. Los fondos de cabaña de morfología tumular: características, proceso de formación y cronología. Veleia 22, 77-110.

Narbarte, J., 2020. Late Medieval and Modern Settlement Dynamics in Three Atlantic Basque Villages: An Approach on the Rural Landscape. In: Grau Sologestoa \& Quirós Castillo, J.A., Arqueología de la Edad Moderna en el País Vasco y su entorno, 103-120. Archaeopress, Oxford

Narbarte, J., Rodríguez Lejarza, A., Olazabal Uzkudun, A., Iriarte Avilés, E., Quirós Castillo, J.A., 2020. Monte compartido, monte dividido. Gestión, apropiación y transformación del paisaje de montaña en la vertiente atlántica del País Vasco: los seles de la sierra de Hernio (siglos XIV-XIX). Historia Agraria.

Odriozola Oyarbide, L., 2002. Construcción naval en el País Vasco, siglos XVI-XIX: evolución y análisis comparativo. Gipuzkoako Foru Aldundia, Donostia.

Olalde Fernández, M., Lizaso Sánchez, I., 2007. La Gestión Forestal en el LIC Aiako Harria. Actas de la Reunión sobre planificación Forestal en la Red Natura 2000. Cuadernos de la Sociedad Española de Ciencias Forestales 21, 155-159.

Olano, J.M., Peralta de Andrés, J., 2009. 9120: Hayedos acidófilos atlánticos con sotobosque de llex y a veces de Taxus (Quercion robori-petraeae o llici-Fagenion). VV.AA., Bases ecológicas preliminares para la conservación de los tipos de hábitat de interés comunitario en España. Ministerio de Medio Ambiente, Madrid.

Otaegui Arizmendi A. 1991. Guerra y crisis de la hacienda local: las ventas de bienes comunales en Guipúzcoa, 17931814. Universitat Autònoma de Barcelona, Barcelona.

Palet, J.M., García Molsosa, A., Orengo Romeu, H.A., Polonio Alamino, T., 2017. Els espais altimontans pirenaics orientals a l'Antiguitat: 10 anys d'estudis en arqueologia del paisatge del GIAP-ICAC. Treballs d'Arqueologia 21, 77-97.

Pardo Navarro, F., Martín Jiménez, E., Gil Sánchez, L., 2003. El uso tradicional de la Dehesa Boyal de Puebla de la Sierra (Madrid): efectos sobre la vegetación a corto y largo plazo. Cuadernos de la Sociedad Española de Ciencias Forestales (Actas de la II Reunión sobre Historia Forestal) 16, 173-178.

Pintó, J. 2010. Les unitats de paisatge, en J. Pintó (ed.): Eines i instruments per a les polítiques de paisatge. Universitat de Girona, Girona

Rackham, O., 1976. Trees and woodland in the British landscape. J.M. Dent, Londres.

Rendu, C., 2003. La montagne d'Enveig, une estive pyrénéenne dans la longue durée. Trabucaire, Perpignan.

Rendu, C., Calastrenc, C., Le Couédic, M., Berdoy, A., 2016. Estives d'Ossau. 7000 ans de pastoralisme dans les Pyrénées. Le pas de l'oiseau, Paris.
Rendu, C., Passarrius, O., Calastrenc, C., Julia, R., Llubes, M., Illes, P., Campmajó, P., Jodry, C., Crabol, D., Bille, E., Conesa, M., Bousquet, D., Lallemand, V., 2015. Reconstructing past terrace fields in the Pyrenees: Insights into land management and settlement from the Bronze Age to the Early Modern era at Vilalta (1650 masl, Cerdagne, France). Journal of Field Archaeology 40(4), 461-480.

Reyes-García, V., Aceituno-Mata, L., Calvet-Mir, L., Garnatje, T., Gómez-Baggethun, E., Lastra, J.J., Ontillera, R., Parada, M., Rigat, M., Vallès, J., Vila, S., Pardo de Santayana, M., 2014. Resilience of traditional knowledge systems: The case of agricultural knowledge in home gardens of the Iberian Peninsula. Global Environmental Change 24, 223-231.

Reyes-García, V., Martí-Sanz, N., 2007. Etnoecología: Punto de encuentro entre naturaleza y cultura. Ecosistemas 16(3), 45-54.

Rigueiro, A., Rodríguez, M.A., Gómez-Orellana, L., 2009. 6230: Formaciones herbosas con Nardus, con numerosas especies, sobre sustratos silíceos de zonas montañosas (y de zonas submontañosas de Europa continental). VV.AA., Bases ecológicas preliminares para la conservación de los tipos de hábitat de interés comunitario en España. Ministerio de Medio Ambiente, Medio Rural y Marino, Madrid.

Rodríguez Fernández, J., Martínez Montecelo, Á., 2018a. Prospección en medio montano y forestal. Arkeoikuska 2018, 223-229.

Rodríguez Fernández, J., Martínez Montecelo, Á., 2018b. Documentación sistemática del arbolado trasmocho: un caso práctico en los Montes Altos de Vitoria. Cuadernos de la Sociedad Española de Ciencias Forestales 38, 157-165.

Stagno, A.M., 2016. Archaeology of Commons: a Multidisciplinary Approach to the Reconstruction of Multiple Uses and Conflicts on European Uplands. Multi-, Inter- and Transdisciplinary Research in Landscape Archaeology. Proceedings of the 3rd International Landscape Archaeology Conference in Rome, Italy (2014)

Stagno, A.M., 2017. Archeologia e storia di uno spazio precario: le colture temporanee tra pratiche collettive e appropriazione privata (Paesi Baschi, XV-XX s.). Quaderni Storici 155, 499-534.

Stagno, A.M., 2018. Gli spazi dell'archeologia rurale. Risorse ambientali e insediamenti nell'Appennino ligure tra XV e XX secolo. All'Insegna del Giglio, Florencia

Stagno, A.M., 2019. Historia de un monte compartido: un enfoque multi-disciplinar para el estudio de las formas históricas de apropiación de la tierra entre Zornoztegi y Udala. En: Quirós-Castillo, J.A. (ed.), Arqueología de una comunidad campesina medieval: Zornoztegi (Álava), 481-514. UPV/EHU, Bilbao.

Stagno, A.M., 2020. A multidisciplinary approach to the relationship between seasonal settlements and multiple uses. Case studies from southern Europe (10th-21st c.). In: Dixon, P., Theune, C. (eds.), Ruralia XIII Seasonal Settlement in the Medieval and Early Modern Countryside. Sidestone Press, Leiden.

Stagno, A.M., Tejerizo-García, C., Echezarreta-Gallego, A., Santeramo, R., Portillo, M., Pescini, V., Hernández-Beloqui, B., 2020. De montes comunes y sociedades campesinas: los resultados del proyecto ARCHIMEDE en el País Vasco. Grau-Sologestoa, I., Quirós-Castillo, J.A. (eds.), Arqueología de la Edad Moderna en el País Vasco y su entorno, 165-181. Archaeopress, Oxford.

Van der Nest, A., Wingfield, M., Janoušek, J., Barnes, I., 2019. Lecanosticta acicola: A growing threat to expanding global pine forests and plantations. Molecular Plant Pathology 20(10), 1327-1364 
